\title{
Epidemiology of Treponema pallidum,
} Chlamydia trachomatis, Neisseria gonorrhoeae, Trichomonas vaginalis, and Herpes simplex virus type 2 among female sex workers in the Middle East and North Africa: systematic review and meta-analytics

\author{
Hiam Chemaitelly ${ }^{1,3}$, \\ Helen A Weiss ${ }^{2,3}$, Alex \\ Smolak$^{1}$, Elzahraa Majed ${ }^{1}$, \\ Laith J Abu-Raddad ${ }^{1,4,5}$ \\ ${ }^{1}$ Infectious Disease Epidemiology \\ Group, Weill Cornell Medicine- \\ Qatar, Cornell University, Qatar \\ Foundation - Education City, \\ Doha, Qatar \\ ${ }^{2}$ MRC Tropical Epidemiology \\ Group, London School of Hygiene \\ and Tropical Medicine, London, \\ United Kingdom \\ ${ }^{3}$ Department of Infectious \\ Disease Epidemiology, Faculty \\ of Epidemiology and Population \\ Health, London School of Hygiene \\ and Tropical Medicine, London, \\ United Kingdom \\ ${ }^{4}$ Department of Healthcare Policy \& \\ Research, Weill Cornell Medicine, \\ Cornell University, New York, New \\ York, USA \\ ${ }^{5}$ College of Health and Life \\ Sciences, Hamad bin Khalifa \\ University, Doha, Qatar
}

\section{Correspondence to:}

Hiam Chemaitelly

Weill Cornell Medicine-Qatar Qatar Foundation-Education City P.O. Box 24144

Doha

Qatar

hsc2001@qatar-med.cornell.edu
Background The epidemiology of sexually transmitted infections (STIs) and the role of commercial heterosexual sex networks in driving STI transmission in the Middle East and North Africa (MENA) region remain largely unknown.

Objective To characterize the epidemiology of Treponema pallidum (syphilis), Chlamydia trachomatis, Neisseria gonorrhoeae, Trichomonas vaginalis, and Herpes simplex virus type 2 (HSV-2) among female sex workers (FSWs) in MENA using an indepth quantitative assessment.

Methods A systematic review on ten international, regional, and country-level databases was conducted, and reported following PRISMA guidelines. Pooled prevalences of current and/or ever infection for each STI were estimated using random-effects meta-analyses. Sources of between-study heterogeneity were investigated through random-effects meta-regressions.

Results One T. pallidum incidence study and 144 STI prevalence studies were identified for 45812 FSWs in 13 MENA countries. The pooled prevalence of current infection was $12.7 \%$ (95\% confidence interval $(\mathrm{CI})=8.5 \%-17.7 \%)$ for T. pallidum, $14.4 \%$ (95\% CI =8.2\%-22.0\%) for C. trachomatis, $5.7 \%$ (95\% CI=3.5\%$8.4 \%)$ for $N$. gonorrhoeae, and $7.1 \%(95 \% \mathrm{CI}=4.3 \%-10.5 \%)$ for $T$. vaginalis. The pooled prevalence of ever infection (seropositivity using antibody testing) was $12.8 \%$ (95\% CI=9.4\%-16.6\%) for T. pallidum, 80.3\% (95\% CI=53.2\%-97.6\%) for C. trachomatis, and $23.7 \%$ (95\% CI=10.2\%-40.4\%) for HSV-2. The multivariable meta-regression for T. pallidum infection demonstrated strong subregional differences, with the Horn of Africa and North Africa showing, respectively 6-fold (adjusted odds ratio (AOR): 6.4; 95\% CI=2.5-16.7) and 5-fold ( $\mathrm{AOR}=5.0 ; 95 \%$ $\mathrm{CI}=2.5-10.6)$ higher odds of infection than Eastern MENA. There was also strong evidence for declining T. pallidum odds of infection at $7 \%$ per year $(A O R=0.93$; 95\% CI=0.88-0.98). Study-specific factors including diagnostic method, sample size, sampling methodology, and response rate, were not associated with syphilis infection. The multivariable model explained $48.5 \%$ of the variation in T. pallidum prevalence.

Conclusions STI infection levels among FSWs in MENA are considerable, supporting a key role for commercial heterosexual sex networks in transmission dynamics, and highlighting the health needs of this neglected and vulnerable population. Syphilis prevalence in FSWs appears to have been declining for at least three decades. Gaps in evidence persist for multiple countries. 
The burden of sexually transmitted infections (STIs) and sequelae remains a major global health concern [1]. Nearly one million persons are infected with a curable STI every day [2], and about half a billion are living with Herpes simplex virus type 2 (HSV-2) [3]. The largely asymptomatic nature of STIs, particularly for women, leaves most individuals unaware of their infection [1]. STIs have been associated with HIV acquisition [4-6], and poor reproductive health outcomes including pelvic inflammatory disease, ectopic pregnancy, infertility, and perinatal deaths $[1,7]$.

Commercial heterosexual sex networks (CHSNs) are believed to play a critical role in STI transmission [8-10]. STIs have been demonstrated as proxy biomarkers of sexual risk behaviour [11,12], and as a powerful tool for understanding the structure of sexual networks and predicting HIV epidemic potential [1113]. However, unlike HIV, STI epidemiology in CHSNs remains, globally, a neglected area of research [1]. Programmatically, STI surveillance among female sex workers (FSWs) continues to be weak and infection levels poorly quantified [1]. Sexual propagation of STIs along CHSNs is also poorly understood given the dearth or limited validity of self-reported sexual behaviour data [13-15].

To attend to the United Nations' Sustainable Development Goals (SDGs) and targets [16], particularly SDG3 target of "ensuring universal access to sexual and reproductive health services" [16], and to reduce the global burden of disease attributed to STIs, the World Health Organization (WHO) has recently formulated the "Global Health Sector Strategy on STIs" [6]. The goal of this strategy is to eliminate STIs as a major public health concern by 2030 through an integrated approach for prevention and control [6]. Milestones for 2020 include achieving 70\% coverage for comprehensive STI prevention services among key populations [6]. The strategy's first strategic direction entails "understanding the STI epidemic as a basis for advocacy, political commitment, national planning, resource mobilization and allocation, implementation, and programme improvement" [6].

Despite remarkable progress in HIV research [17], and an understanding of the role of FSWs [18], people who inject drugs (PWID) [19], and men who have sex with men (MSM) [20], in the HIV epidemic in the Middle East and North Africa (MENA) region, the epidemiology of STIs and the role of CHSNs in driving STI transmission remain largely unknown [21]. The two global reviews of STI epidemiology in FSWs had no data for any of the 23 MENA countries [22,23]. A large volume of STI data in the region resides in databases that were never analyzed, or in country-level reports that were never published in the scientific literature [24,25].

Against this background, our study aimed to characterize the epidemiology of key STIs among FSWs in MENA by 1) systematically reviewing and synthesizing all available published and unpublished evidence for Treponema pallidum (henceforth referred to as syphilis), Chlamydia trachomatis, Neisseria gonorrhoeae, Trichomonas vaginalis, and HSV-2 incidence and/or prevalence, 2) estimating, for each STI, the pooled mean prevalence of current and/or ever (seropositivity using antibody testing) infection, and 3) identifying sources of between-study heterogeneity, and regional and temporal trends associated with STI prevalence.

\section{METHODS}

We conducted a systematic review and an in-depth quantitative assessment to characterize STI epidemiology among FSWs in MENA. Details of the study methodology (including specific statistical analyses) can be found in subsequent sections.

\section{Search strategy and selection criteria}

Evidence for syphilis, C. trachomatis, N. gonorrhaoeae, T. vaginalis, and HSV-2 immunoglobulin G (IgG) incidence and/or prevalence among FSWs in MENA was systematically reviewed, informed by Cochrane's Collaboration guidelines [26]. Findings were reported following Preferred Reporting Items for Systematic Reviews and Meta-analyses (PRISMA) guidelines [27] (checklist in Table S1 in Online Supplementary Document). The MENA definition covers 23 countries-Afghanistan, Algeria, Bahrain, Djibouti, Egypt, Iran, Iraq, Jordan, Kuwait, Lebanon, Libya, Morocco, Oman, Pakistan, Palestine, Qatar, Saudi Arabia, Somalia, Sudan, Syria, Tunisia, United Arab Emirates (UAE), and Yemen-based on convention in HIV research [19,20,24,25], and definitions of WHO, Joint United Nations Programme on HIV/AIDS (UNAIDS), and World Bank [24].

Systematic searches were performed up to September 20, 2018, on international databases (PubMed and Embase), regional and national databases (WHO Global Health Observatory data repository [28], WHO 
African Index Medicus database, WHO Index Medicus for the Eastern Mediterranean Region database, Iranian Scientific Information Database, Iraqi Academic Scientific Journals' database, and Pakistan's PakMediNet database), abstract archives of International AIDS Society Conferences [29], as well as published and unpublished country-level and international organizations' reports available through the MENA HIV/ AIDS Epidemiology Synthesis Project database [24,25]. Search strings were broad (MeSH/Emtree terms exploded to cover all subheadings and free text terms) with no language or year restrictions (Box S1 in Online Supplementary Document).

Duplicate citations were identified using a reference manager, Endnote. Titles and abstracts were then screened for relevance, with relevant/potentially relevant citations undergoing full-text screening. Any document reporting an incidence and/or prevalence measure in FSWs for an STI of interest, based on primary data, was eligible for inclusion. Case reports, case series, editorials, commentaries, and reviews were excluded. Hand searching was further performed on reference lists of all relevant articles.

The term 'study' is used here to refer to a specific STI incidence or prevalence measure in a specific FSW population. Accordingly, one document/report could contribute multiple studies and one study could be published in different reports. Duplicate study results were included only once using the more detailed/ recent report.

\section{Data extraction and synthesis}

Extraction was performed by HC, and double extraction by AS (extraction list in Box S2 in Online Supplementary Document). Discrepancies were settled by consensus, or by contacting authors. Full-texts in languages other than English were extracted by native speakers. Data were stratified by infection type (current vs ever (seropositivity using antibody testing)), and summarized using medians, ranges, and interquartile ranges (IQR). Definitions of infection types and details of the classification of diagnostic methods' results into current, recent, and ever infection can be found in Table S2 in Online Supplementary Document. It was assumed, for N. gonorrhoeae and T. vaginalis studies, whenever a diagnostic method was not explicitly specified, that the diagnostic method assessed current infection.

All STI studies were extracted and reported. However, studies applying the same assay to different biological specimens from the same person were included only once in analyses, for statistical independence. This was done based on a sequential order that prioritized infection detection in endocervical swabs, followed by vaginal, then urine samples. Studies assessing prevalence using different diagnostic methods, were also included only once in analyses, with studies using polymerase chain reaction prioritized over those using culture or other methods.

\section{Quality assessment}

The quality assessment for each STI prevalence study was informed by Cochrane Collaboration guidelines (criteria in Table S3 in Online Supplementary Document) [30]. Studies were classified as having "low" vs "high" risk of bias (ROB) on each of three quality domains assessing the 1) rigor of sampling methodology (probability-based; non-probability-based), 2 ) response rate ( $\geq 60 \%$ or $\geq 60 \%$ of target sample size reached for studies using respondent-driven or time-location sampling; <60\%), and 3) STI ascertainment (biological assay explicitly indicated; otherwise). Studies with missing information for a specific domain were classified as having "unclear" ROB for that domain.

Given reported limitations in HSV-2 diagnostics [31,32], the quality of HSV-2 assays was determined by consulting with an expert advisor, Professor Rhoda Ashley-Morrow, University of Washington, Seattle. Studies where the validity of the diagnostic method could not be confirmed, were excluded from the systematic review.

Quality domains were included in meta-regression analyses (described below) to assess their impact on prevalence.

\section{Meta-analyses}

For each STI, the pooled mean prevalence of current and/or ever infection, along with the corresponding 95\% confidence intervals (CIs), were estimated using meta-analysis. Overall prevalence measures were replaced by their strata where applicable. For each study, one final stratification was considered based on a pre-defined sequential order that prioritizes country of origin, followed by type of FSW, year, region, and age. Subregional and time-trend analyses were conducted as warranted by data. Variances were stabilized using Freeman-Tukey type arcsine square-root transformation $[33,34]$. Weights were applied using 
the inverse-variance method [34,35], before pooling measures using a Dersimonian-Laird random-effects model [36], thereby accounting for sampling variation and for true heterogeneity [37]. Missing sample sizes for measures or their strata ( $<4 \%$ of all studies) were imputed using the median sample size, as calculated from studies with available information.

Heterogeneity assessment used Cochran's Q statistic to confirm existence of heterogeneity across studies, $\mathrm{I}^{2}$ to determine magnitude of between-study variation that is due to true differences in effect size (prevalence) rather than chance, and prediction intervals to estimate the $95 \%$ interval of the true effect sizes' distribution $[37,38]$.

Meta-analyses were implemented in R 3.4.2 (R core team, Vienna, Austria) [39].

\section{Meta-regressions}

Only syphilis had a considerable number of measures ( $>100)$ to warrant conduct of random-effects meta-regression analyses. Independent variables considered a priori were: country/subregion, year of data collection, infection type, diagnostic method, STI ascertainment, sample size, sampling methodology, and response rate. Details of subgrouping and justifications are in Table S4 in Online Supplementary Document. Meta-regression was conducted using the log-transformed odds of syphilis infection and corresponding variance. Factors associated with higher odds of infection at $P \leq 0.10$ in univariable analyses were included in the multivariable analysis. Factors with $P \leq 0.05$ in the multivariable model were considered as significant predictors of heterogeneity in syphilis prevalence.

Meta-regressions were implemented in Stata/SE 15.1 (StataCorp, College Station, TX, USA) [40].

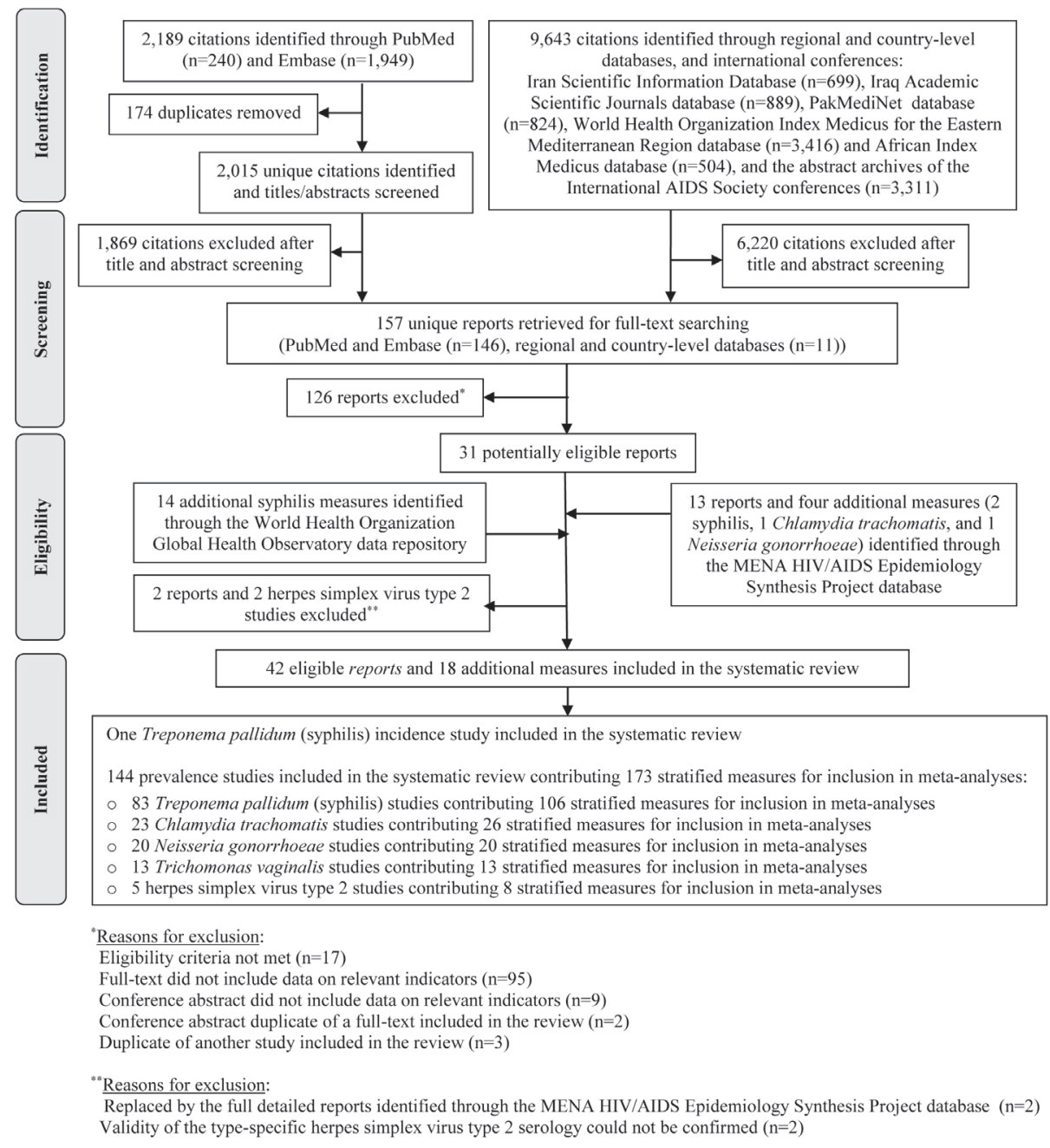

Figure 1. Flowchart presenting the process of study selection following PRISMA guidelines [27]. 


\section{RESULTS}

\section{Search results and scope of evidence}

Figure 1 shows the study selection process based on PRISMA. The search identified a total of 11832 citations: 240 through PubMed, 1949 through Embase, and 9643 through the rest of the databases. After removing duplicates and screening of titles and abstracts, 157 reports qualified for full-text screening, of which 31 were eligible for inclusion in the systematic review.

Thirteen additional reports, two of which replaced eligible articles, and four additional STI measures, were further identified through the MENA HIV/AIDS Epidemiology Synthesis Project database. Fourteen additional syphilis prevalence measures were identified through the WHO Global Health Observatory data repository. Two studies were excluded based on consultation with Professor Rhoda Ashley-Morrow, an expert advisor in HSV-2 diagnostics, because the validity of the type-specific HSV-2 serology could not be confirmed [41,42].

In sum, 42 eligible reports and 18 additional STI measures were included in the systematic review. These yielded one syphilis incidence study, and 144 prevalence studies assessing the different STIs. The latter contributed 173 stratified measures for inclusion in meta-analyses and meta-regressions.

STI prevalence data were available for 45812 FSWs from 13 of the 23 MENA countries. Nearly two-thirds (58.9\%) of prevalence studies assessed syphilis (in 29769 FSWs), 16.3\% assessed C. trachomatis (in 5613 FSWs), 12.8\% assessed N. gonorrhoeae (in $5230 \mathrm{FSWs),} \mathrm{8.5 \%} \mathrm{assessed} \mathrm{T.} \mathrm{vaginalis} \mathrm{(in} 4258 \mathrm{FSWs}$ ), and $3.6 \%$ assessed HSV-2 IgG (in 942 FSWs). Most studies (80.8\%) were conducted post-2000. Over half (51.1\%) of studies reported on current infection, 30.5\% on ever infection (seropositivity using antibody testing), and $1.4 \%$ on recent infection. Time of exposure was unclear for the rest of studies $(17.0 \%)$.

\section{Incidence studies}

The only one identified incidence study assessed syphilis incidence in FSWs. The study was conducted in 1988 in Mogadishu, Somalia, and reported cumulative incidence at 12.5\% after six months of follow-up [43].

\section{Prevalence studies}

Prevalence of current syphilis infection among FSWs ranged, across studies $(n=28)$, from 0\%-50.8\%, with a median of 9.4\% (IQR: 3.0\%-23.4\%; Table 1). Meanwhile, seropositivity for syphilis ( $\mathrm{n}=33$ ) antibodies ranged from 0\%-69.0\%, with a median of 4.2\% (IQR: $1.9 \%-15.2 \%$ ).

Current C. trachomatis infection prevalence $(\mathrm{n}=14)$ ranged from $0.7 \%-72.9 \%$, with a median of $7.7 \%$ (IQR $=1.7 \%-22.4 \%$ ), while seropositivity prevalence using IgG $(n=5)$ ranged from $19.8 \%-100 \%$, with a median of $85.8 \%$ (IQR $=46.8 \%-97.1 \%$; Table 2). Two studies reported recent $C$. trachomatis infection (assessed using serological biomarkers) at 29.2\% [79] and 95.0\% [78] .

Current $N$. gonorrhoeae infection prevalence $(n=18)$ ranged from $0 \%-14.5 \%$, with a median of $7.6 \%$ (IQR $=1.3 \%-11.1 \%$; Table 2). Current T. vaginalis infection prevalence $(\mathrm{n}=12)$ ranged from $0 \%-19.3 \%$, with a median of $7.0 \%$ (IQR = 4.5\%-14.2\%; Table 2). HSV-2 seropositivity (using IgG; $n=5)$ ranged from 4.7\%$55.5 \%$, with a median of $20.0 \%$ (IQR $=6.4 \%-39.1 \%$; Table 3$)$.

\section{Quality assessment}

The summarized and study-specific ROB assessments of prevalence measures are in Tables S5 and S6 in Online Supplementary Document, respectively. Briefly, nearly half of studies (44.7\%) used probability-based sampling. Most studies (78.7\%) indicated explicitly the biological assay used for STI ascertainment. Response rate information was missing in over half of studies (51.8\%).

Overall, studies were of reasonable quality. Close to $60 \%$ of studies had low ROB on at least two quality domains, and none had high ROB on two or more domains.

\section{Pooled mean prevalence estimates}

Table 4 shows the results of meta-analyses estimating the pooled mean prevalence of current and/or ever infection for each STI. The mean prevalence of current infection was estimated at $12.7 \%$ (95\% CI = 8.5\%- 


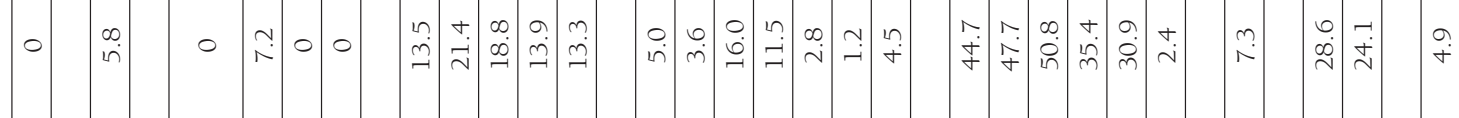

를

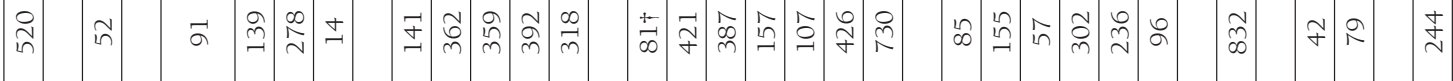

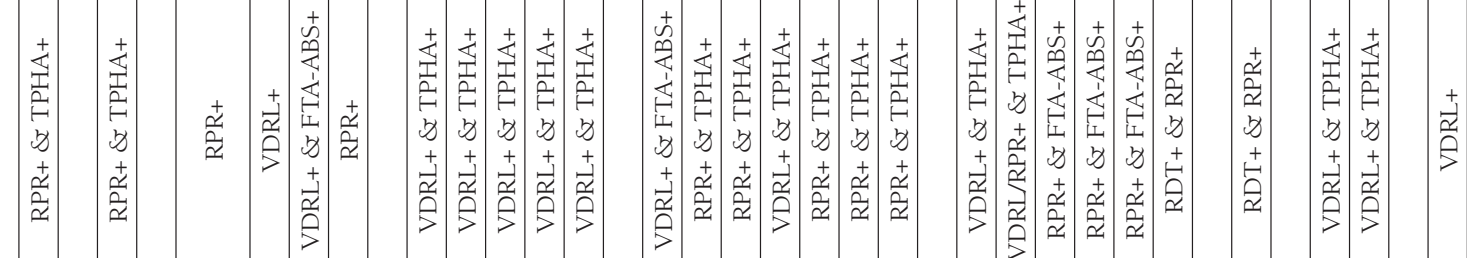

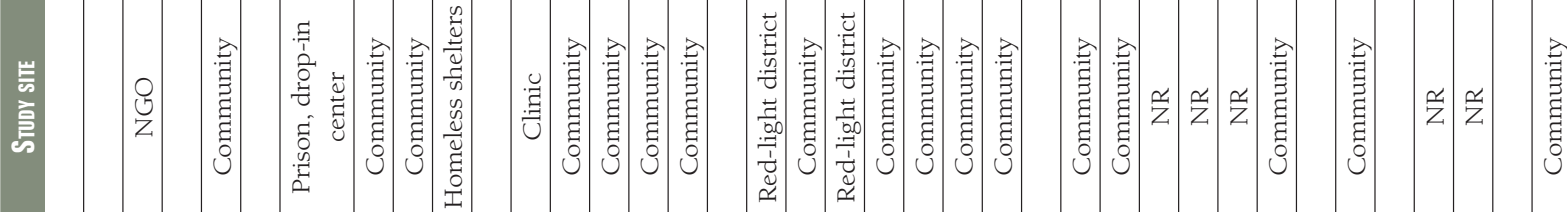

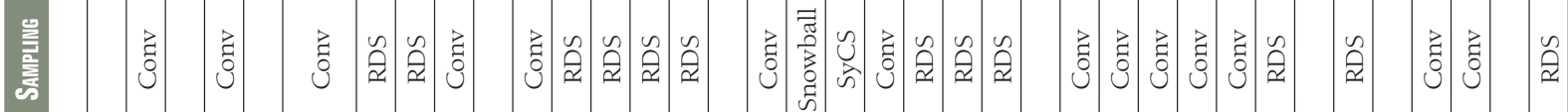

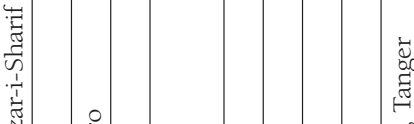
:

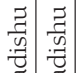

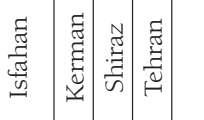

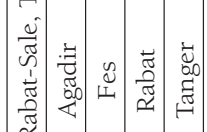

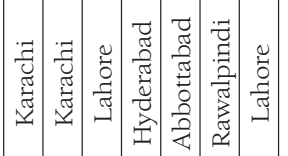

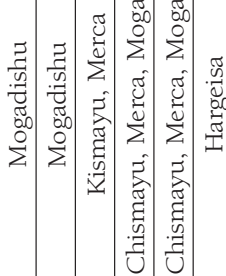

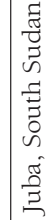

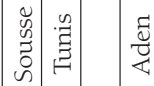

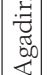

*

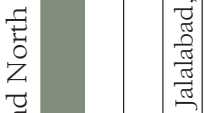

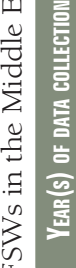

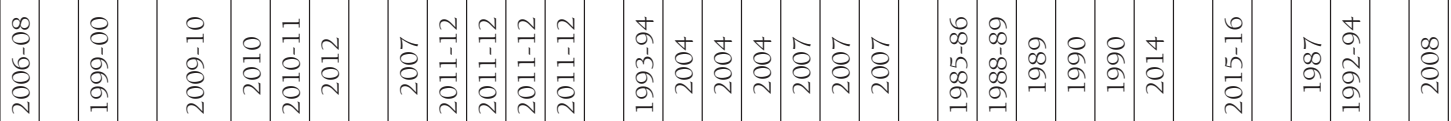

छ్

$\frac{\sqrt{7}}{2}$

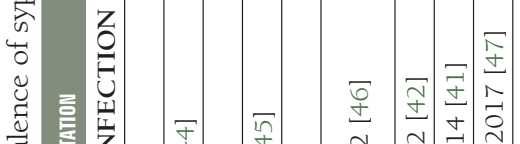

$\bar{\pi}: \overline{\frac{\pi}{n}}$

นิ

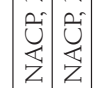

己

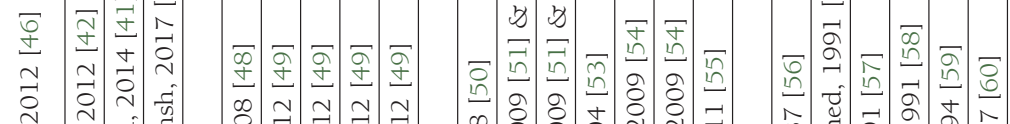

湿

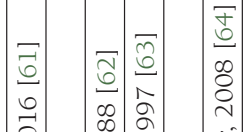

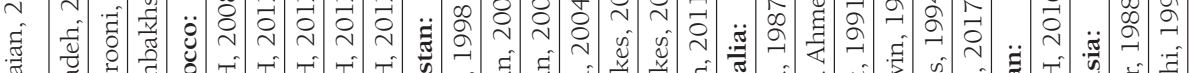

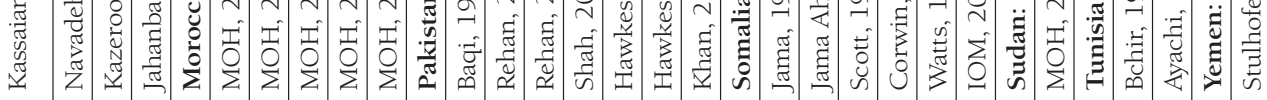




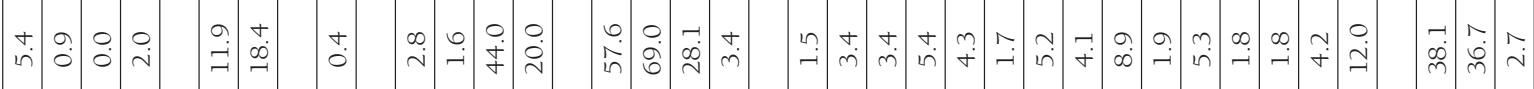

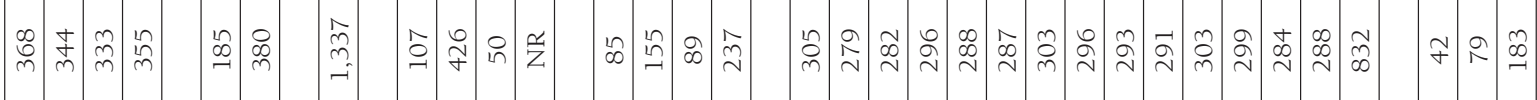

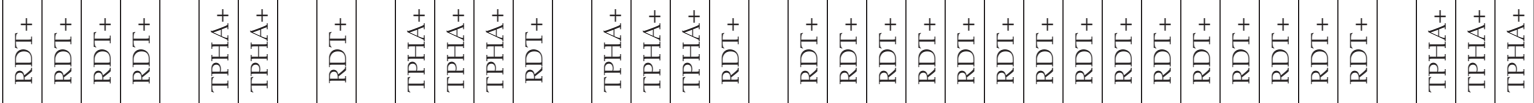

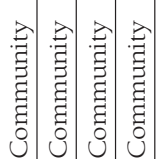

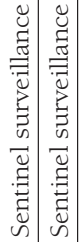

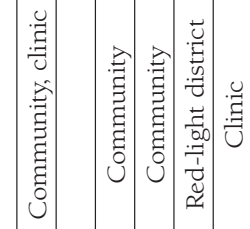

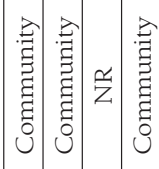

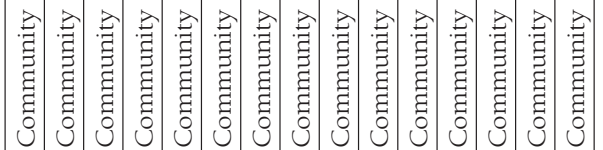

号艺莧

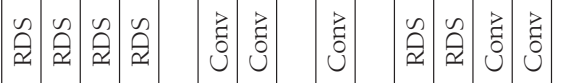

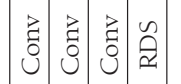

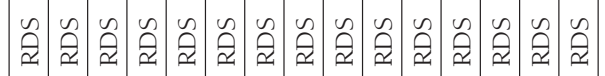

نे

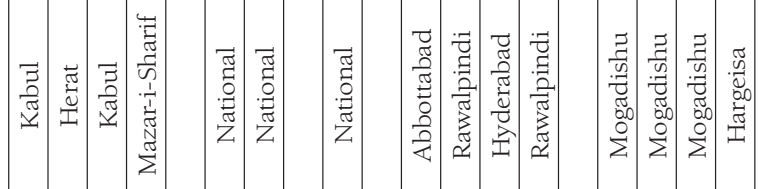

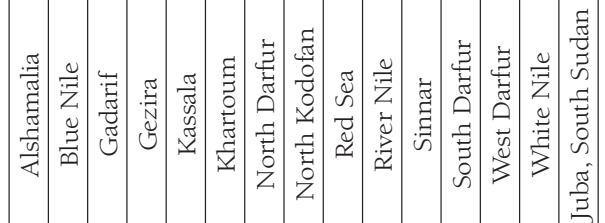

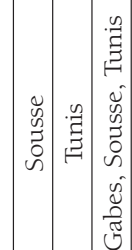

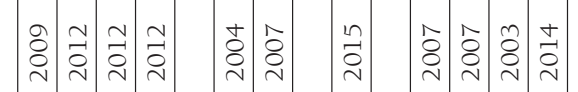

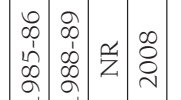

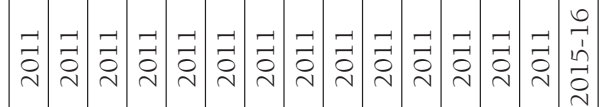

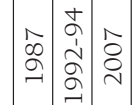

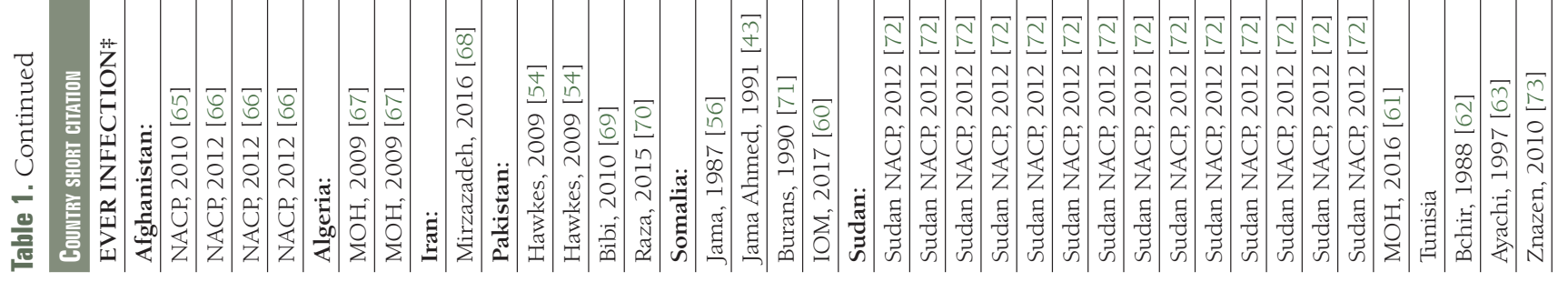




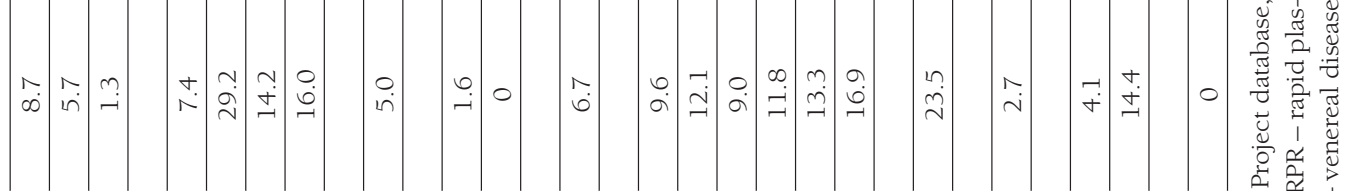

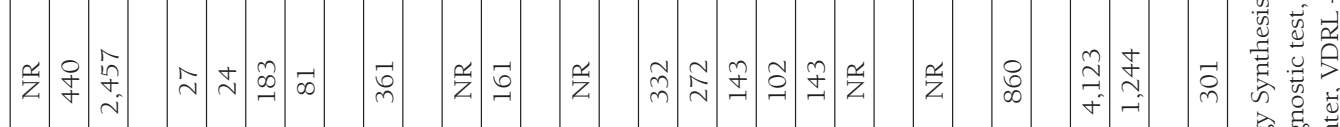

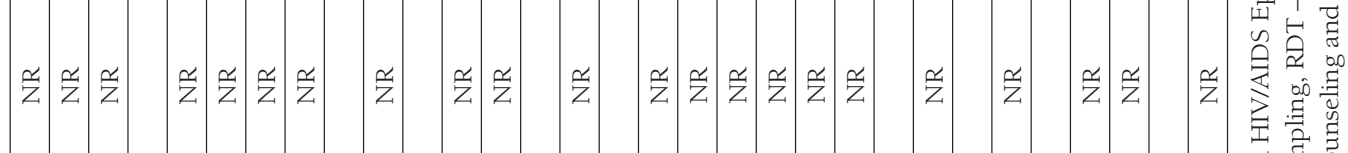

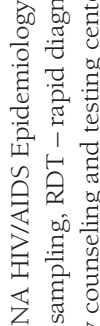

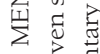

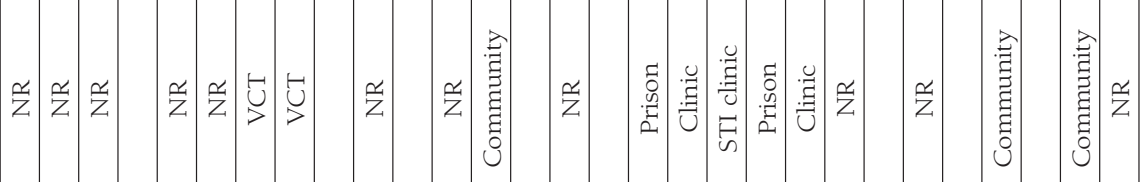

峦妾率

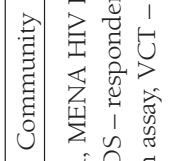

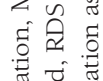

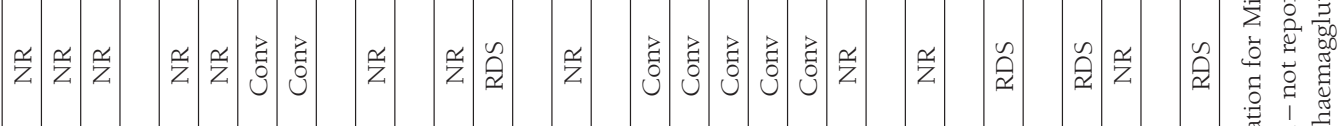

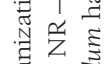

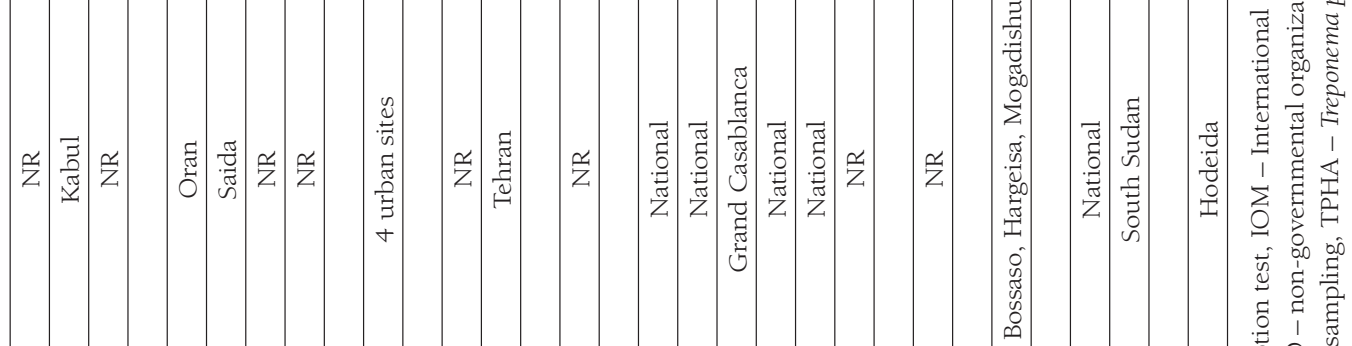

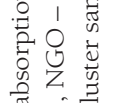

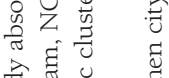

产

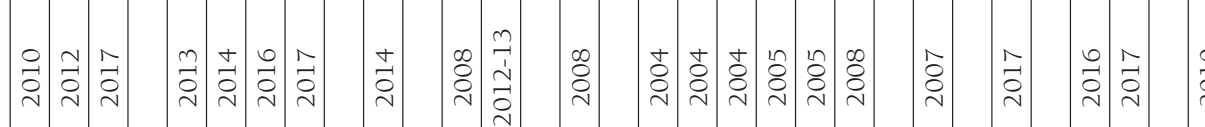

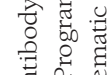

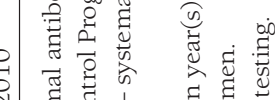

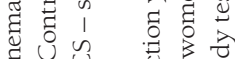

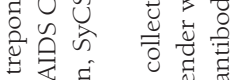

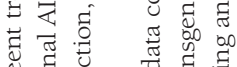

视

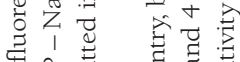

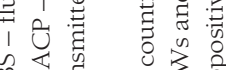

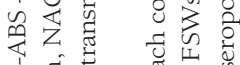

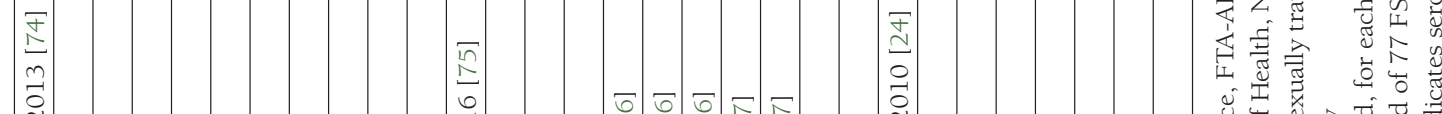

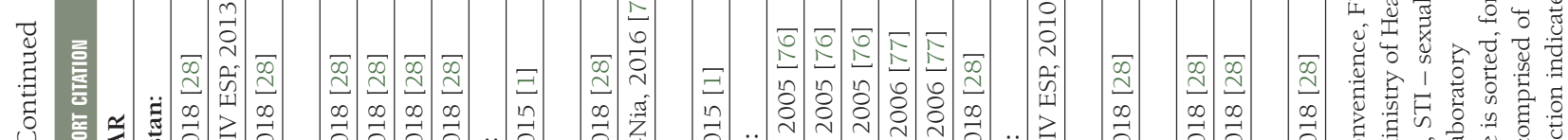

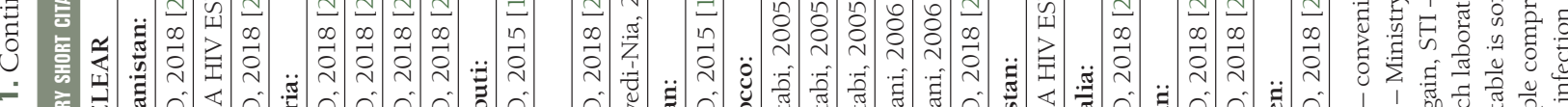

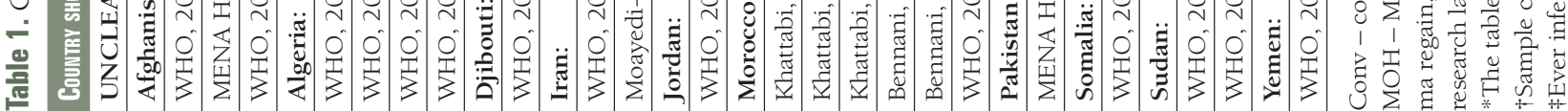




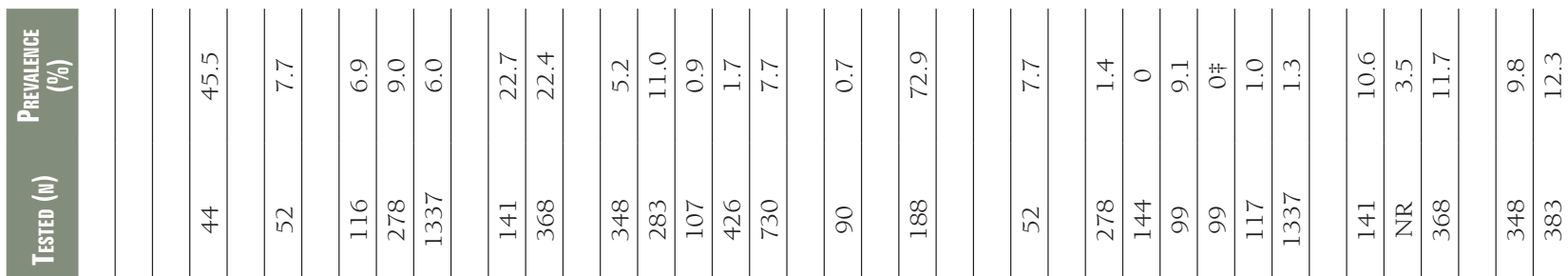

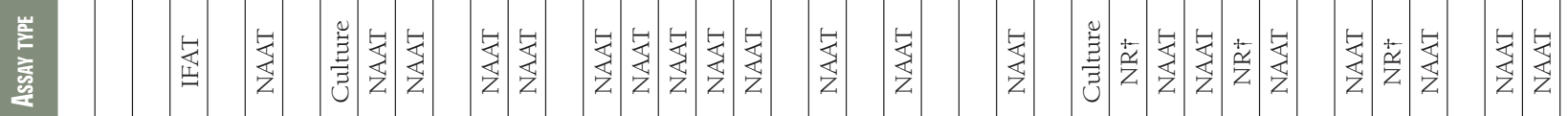

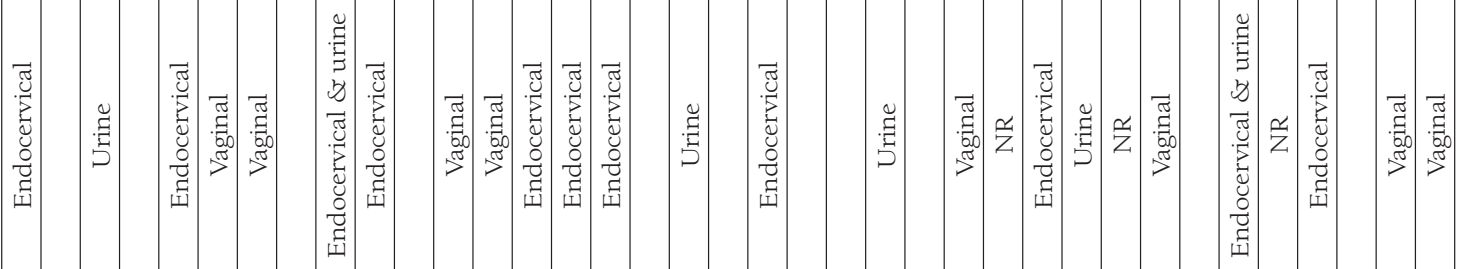

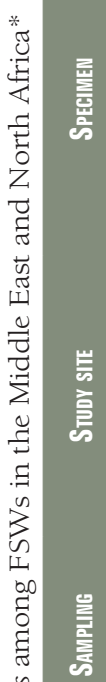

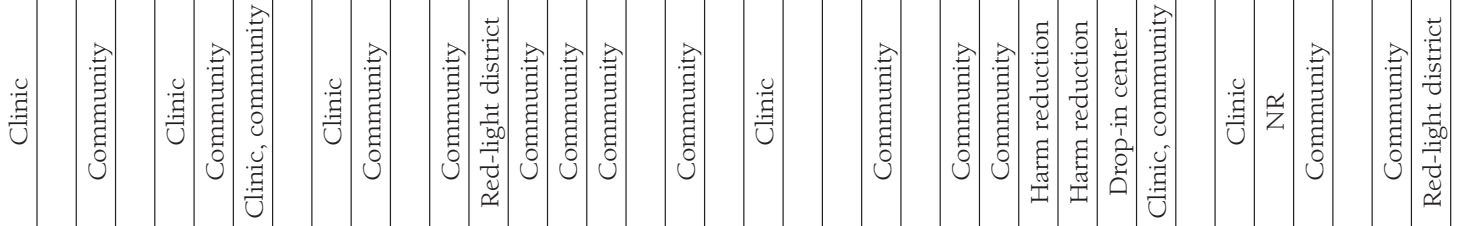

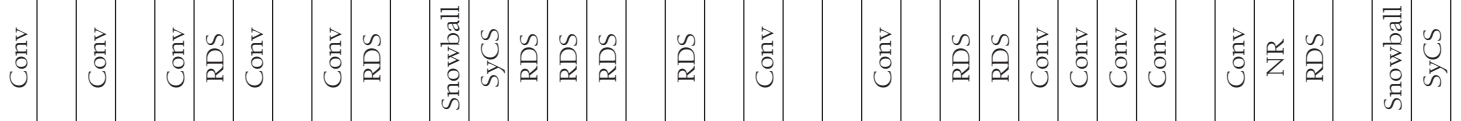

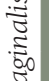

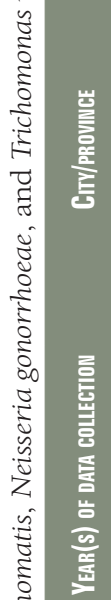

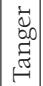

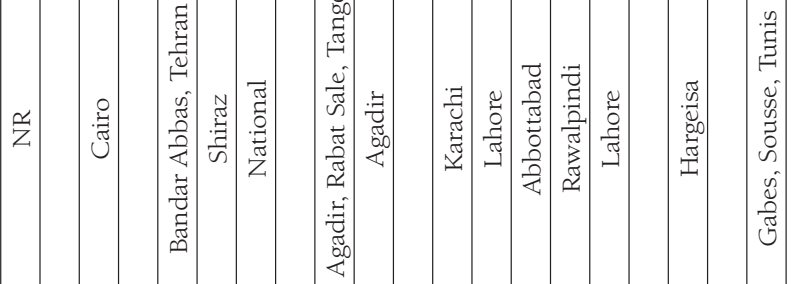

:

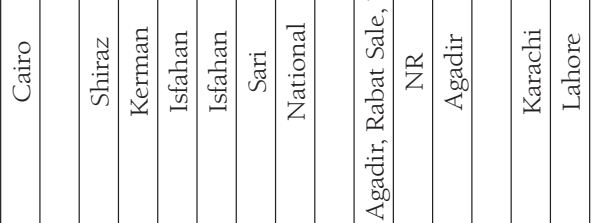

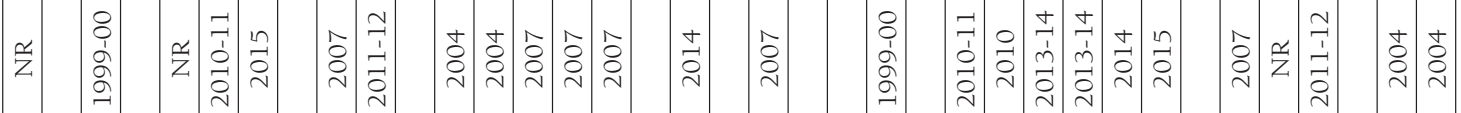

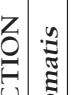

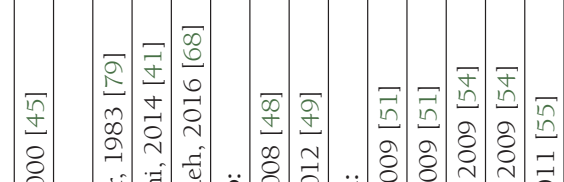

ะ

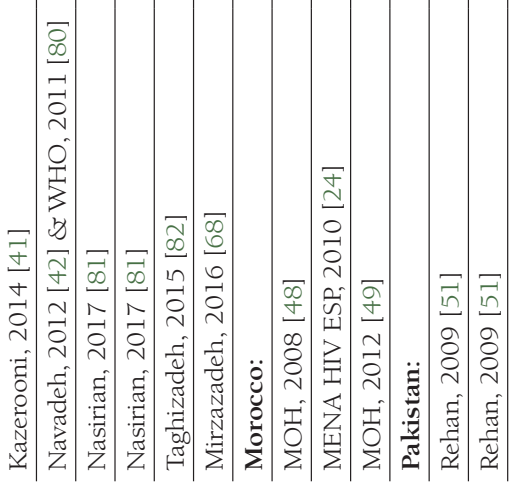




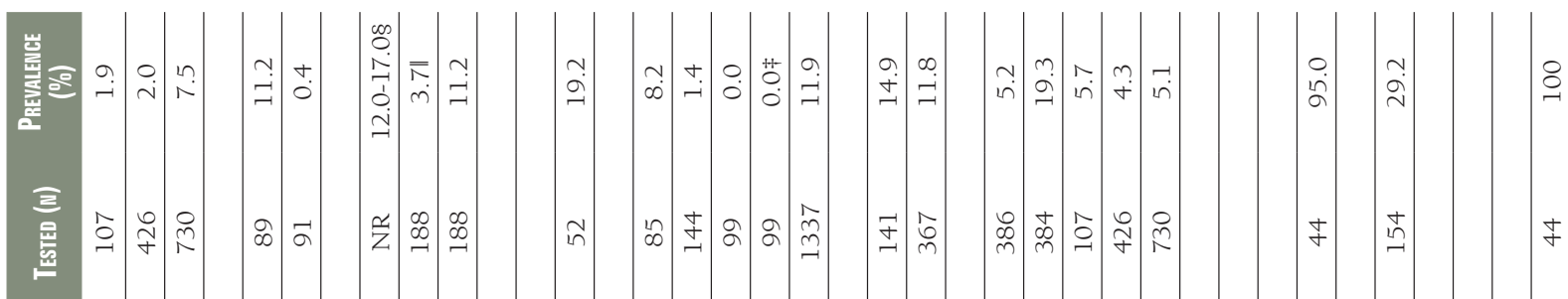

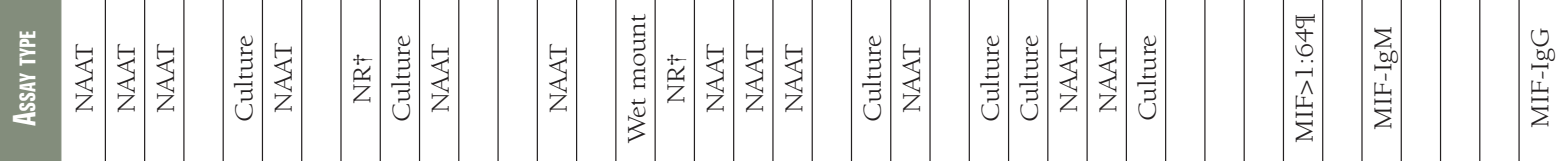

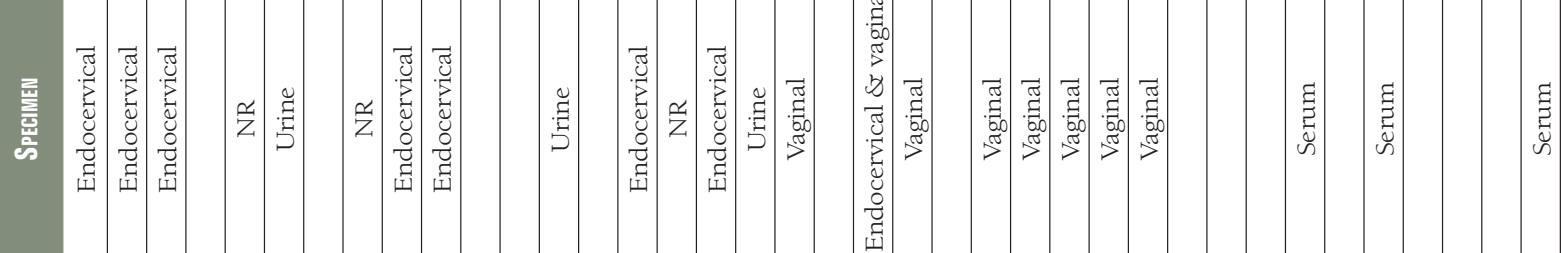

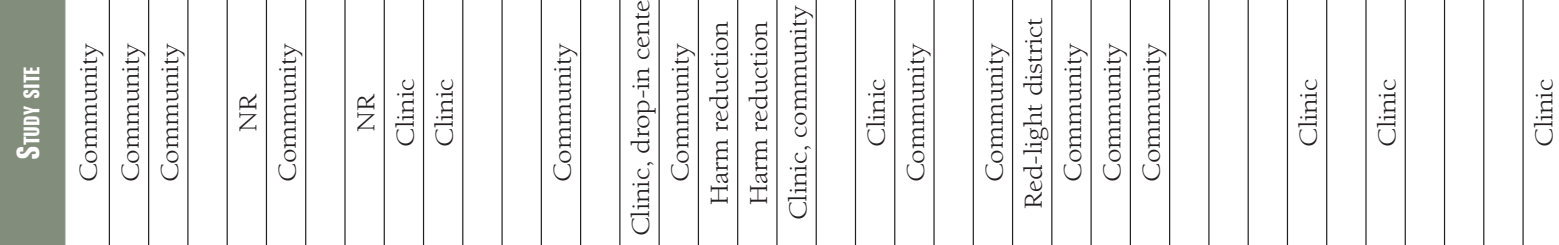

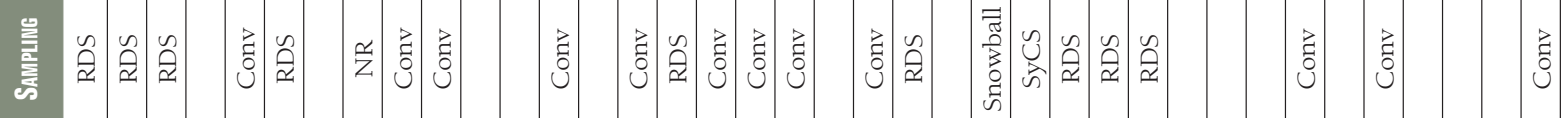

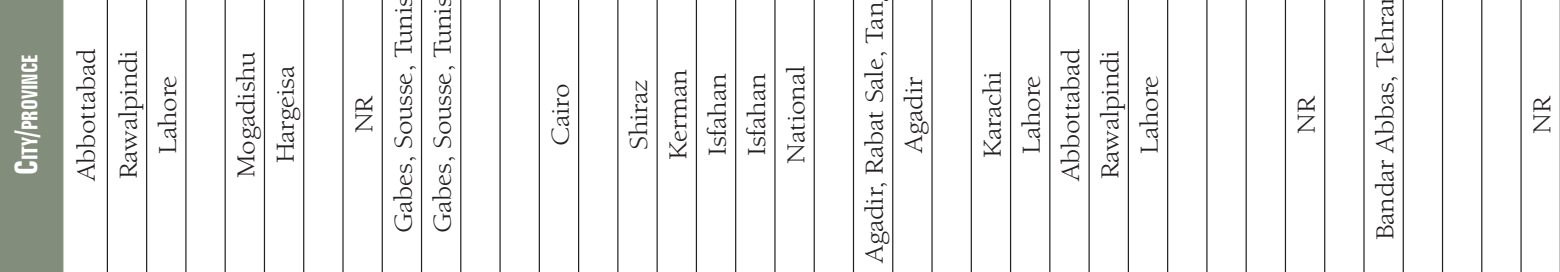

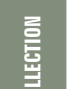

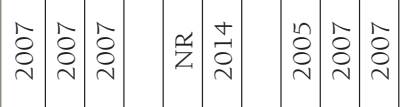

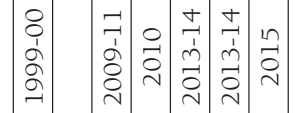

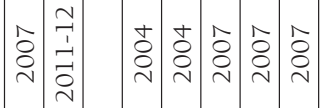

点 点

孚

要

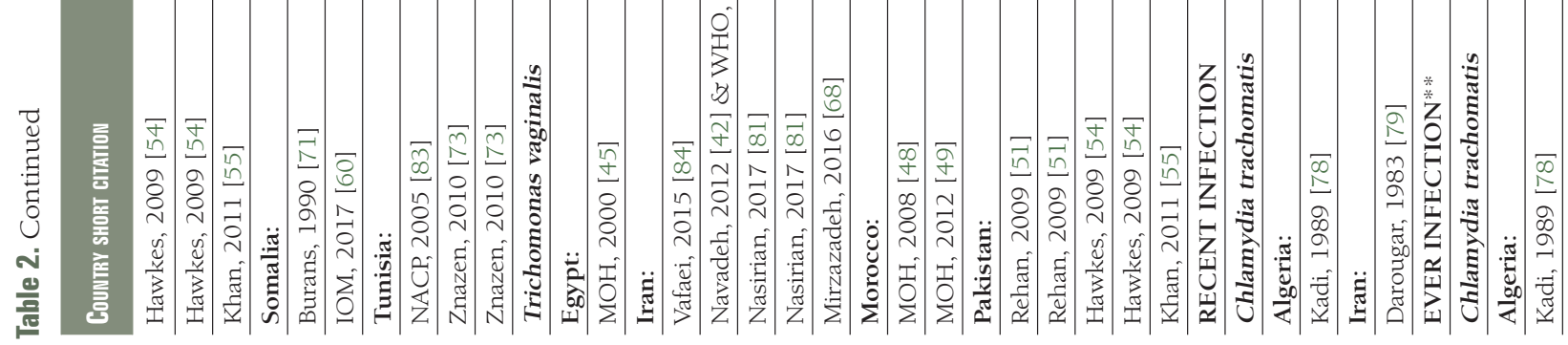




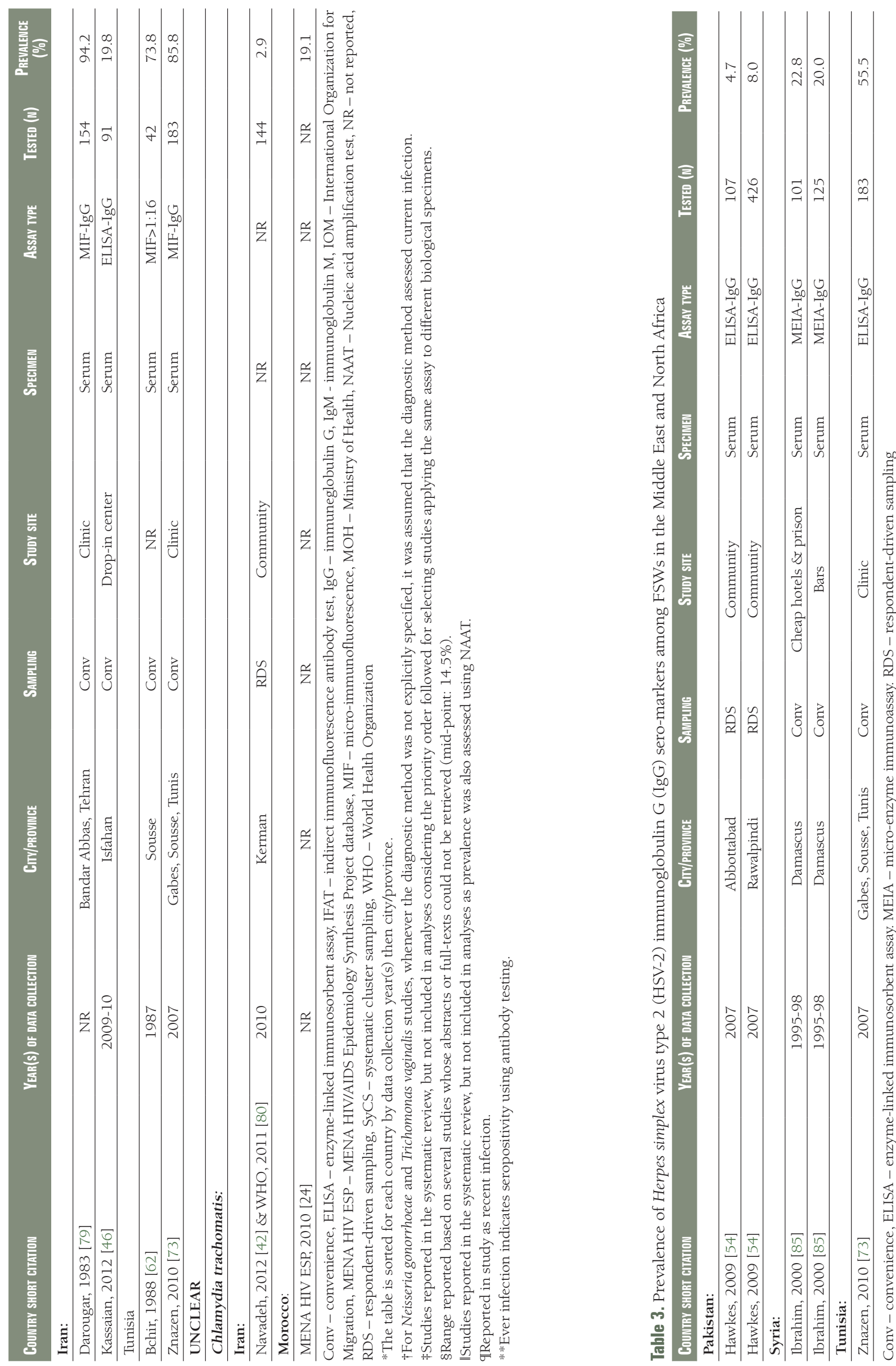


$17.7 \%)$ for syphilis, $14.4 \%$ (95\% CI=8.2\%-22.0\%) for C. trachomatis, $5.7 \%(95 \% \mathrm{CI}=3.5 \%-8.4 \%)$ for N. gonorrhoeae, and $7.1 \%(95 \% \mathrm{CI}=4.3 \%-10.5 \%)$ for $\mathrm{T}$. vaginalis.

The mean prevalence of ever infection was estimated at $12.8 \%$ (95\% CI=9.4\%-16.6\%) for syphilis, $80.3 \%$ (95\% CI=53.2\%-97.6\%) for C. trachomatis, and 23.7\% (95\% CI=10.2\%-40.4\%) for HSV-2 IgG.

There was strong evidence for heterogeneity in effect size (here, prevalence). $P$ for Cochran's $Q$ statistic was always $<0.0001$. $\mathrm{I}^{2}$ was $>90 \%$ in all meta-analyses, indicating that most variability is due to true differences in effect size across studies, rather than being due to chance. Prediction intervals were also wide affirming high heterogeneity.

Additional meta-analyses at the subregional level indicated the mean prevalence of current syphilis infection at 3.0\% (95\% CI=0.9\%-9.2\%) in Eastern MENA, 17.6\% (95\% CI = 14.2\%-21.3\%) in North Africa, and $27.8 \%$ (95\% CI=15.2\%-42.4\%) in the Horn of Africa (Table S7 in Online Supplementary Document). There was also a tendency for a decline in current infection prevalence post-2010 (Table S8 and Figure S1A in Online Supplementary Document). For the rest of the STIs, the number of studies was small and the CIs were wide and overlapping to warrant conclusive statement about the temporal trend (Table S8 in Online Supplementary Document).

\section{Predictors of variability in syphilis infection}

Country/subregion, year of data collection, diagnostic method, sample size, sampling methodology, and response rate were associated with higher odds of syphilis infection in the univariable meta-regression analyses. These were, therefore, included in the multivariable model (Table 5). About a third of the variability was explained by each of year of data collection and subregion (adjusted R-squared: 34.6\% and $31.5 \%$, respectively). Meanwhile, no evidence for an association with infection type (current infection; ever infection), or STI ascertainment (biological assay explicitly indicated; otherwise) was found.

The multivariable analysis showed strong evidence for subregional differences, with Horn of Africa and North Africa showing, respectively, 6-fold (adjusted odds ratio (AOR): 6.4; 95\% CI=2.5-16.7) and 5-fold $(A O R=5.0 ; 95 \% C I=2.5-10.6)$, higher odds of syphilis infection than Eastern MENA.

There was also strong evidence for a temporal trend of decreasing odds of infection at $7 \%$ per year $(\mathrm{AOR}=0.93 ; 95 \% \mathrm{CI}=0.88-0.98$; linearity dictated by data (Figure S1 in Online Supplementary Document) over the last three decades. Although this trend was noted in all subregions, individual subregion meta-regressions were not always powered to detect statistical significance (not shown).

No evidence for an association with diagnostic method, sample size, sampling methodology, and response rate was identified in the multivariable model. The multivariable model explained $48.5 \%$ of variation in syphilis prevalence.

\section{DISCUSSION}

We provided, to our knowledge, the first detailed assessment of the epidemiology of key STIs in FSWs in MENA, a neglected key population. Our findings indicated substantial STI prevalence, several folds higher than that among the general population $[2,13,24,86]$. These findings suggest a major role for CHSNs in driving STI transmission in MENA. We further found large heterogeneity in syphilis infection levels by subregion within MENA, as well as a trend of decreasing odds of infection by $7 \%$ per year - less than the 17\% [86] annual decline needed to achieve the target of $90 \%$ reduction in syphilis incidence by 2030 [6].

Despite the significant infection burden, STI surveillance and response in MENA continue to be rudimentary [21], and far below the coverage targets of WHO Global Health Sector Strategy for STIs [6]. Infected individuals are often identified through routine case notifications with surveillance/testing being largely limited to HIV $[21,24,87]$, and sexual health programs, where they exist, cater to general population women rather than women at high risk [24].

Although our expansive search identified considerable evidence at the regional-level, including data that will appear in the scientific literature for the first time, evidence varied by country. Over half of countries had no data on any of the STIs in this key population, less than a third had data on C. trachomatis, N. gonorrhoeae, or T. vaginalis, and only three countries had data on HSV-2 IgG (Table 1, Table 2 and Table 3). This outcome is of concern, given the considerable, yet preventable, STI infection burden among FSWs in the region (Table 4), and the major "core group" role that CHSNs play in STI transmis- 


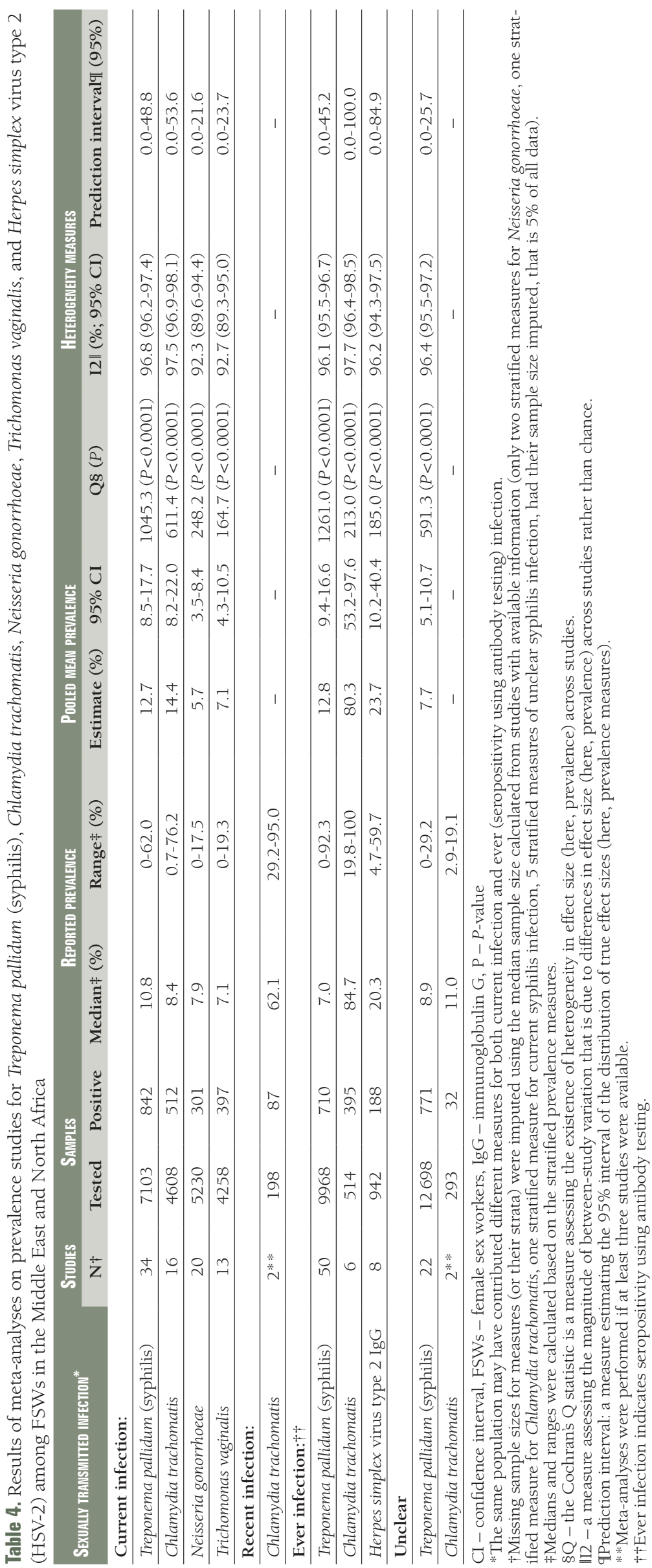

sion in any population [10]. Indeed, while the population proportion of FSWs (proportion of FSWs out of the total women population) varies across countries and may seem relatively small $[18,88]$, the size of CHSNs is large suggesting a considerable number of women and men at risk of STI-related morbidity, either through engagement in high sexual risk behavior, or through onward infection transmission [89].

Availability of STI data stands in contrast to HIV data, for which the volume of evidence among FSWs was several fold higher and encompassed most countries [18]. Attending to WHO Global Health Sector Strategy on STIs [6] necessitates a major expansion of STI research and surveillance, as has been done for HIV $[17,87,90]$. Regrettably, integrated bio-behavioural surveillance surveys (IBBSS) among key populations continue to be focused on HIV, rarely incorporating STIs [91,92]. This presents an important, yet lost, opportunity for monitoring STI levels and trends in key populations, informing programming efforts, gaining an in-depth understanding of sexual networks' structure, and advancing STI research in this region $[13,91,93]$.

Subregion and time explained most variation in syphilis prevalence-each explained over a third of the variation, and both (remarkably) explained $50 \%$ of the variation (Table 5). The strong subregional differences, with Horn of Africa showing the highest prevalence, followed by North Africa, and then Eastern MENA (Table 5 and Table S7 in Online Supplementary Document), appear to reflect variability in the risk environment, such as differences in structure of sexual networks [24], condom use [18], and access to care [24]. The same pattern has been seen in HIV epidemiology among FSWs [18].

There was strong evidence for a time trend of decreasing odds of infection at $7 \%$ per year (Table 5, and Table S8 and Figure S1 in the OSD), consistent with, but smaller than, the decline reported for the general population in MENA in a recent global analysis [86], and the declines reported for the general populations in other regions [86]. Different factors may have contributed to this trend including safer sex following the HIV epidemic [94], increased condom use to prevent unwanted pregnancy [18], and HIV-related mortality which may have disproportionally affected populations at higher risk of STIs [95]. This may have been also a consequence of a shorter 


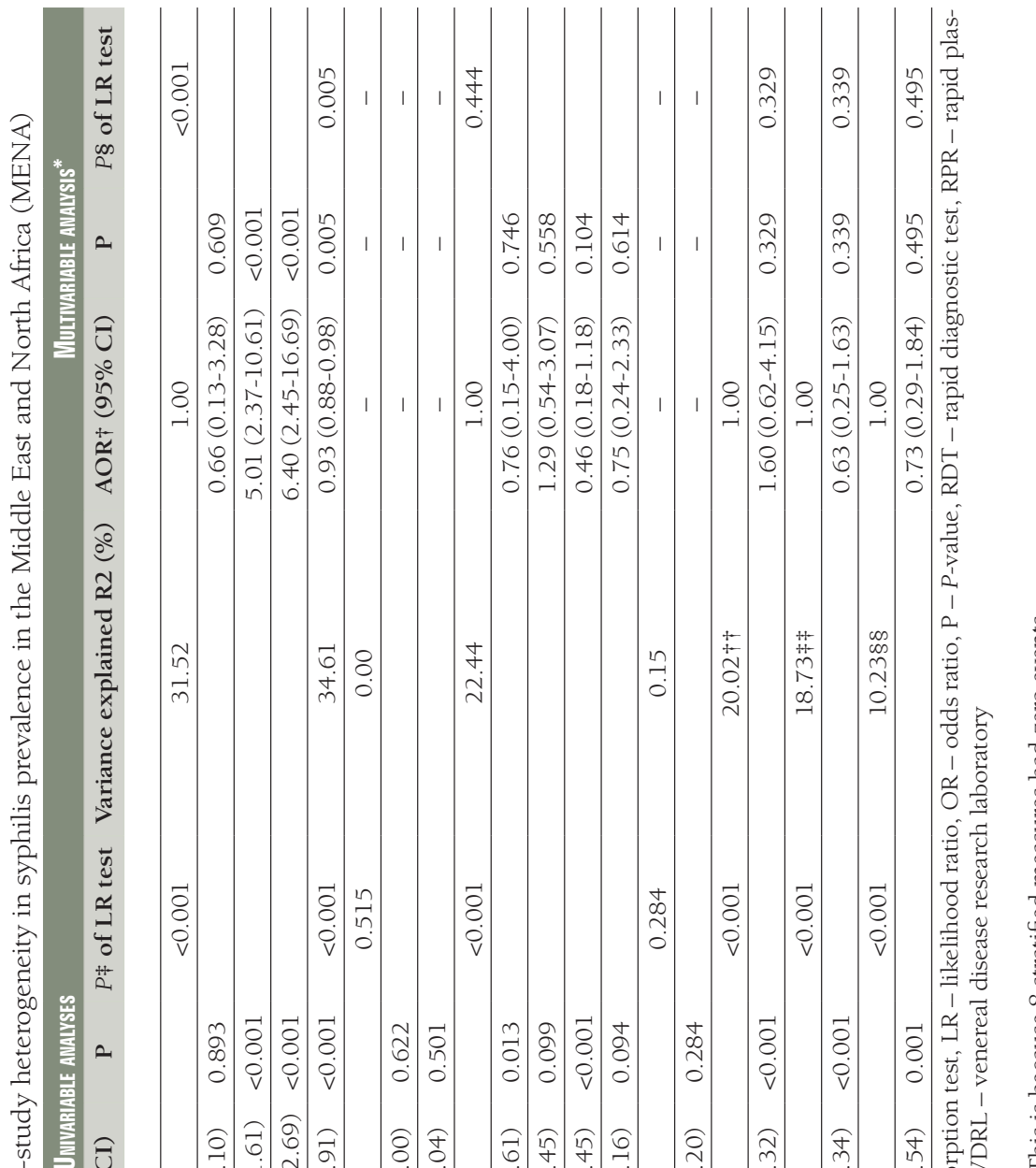

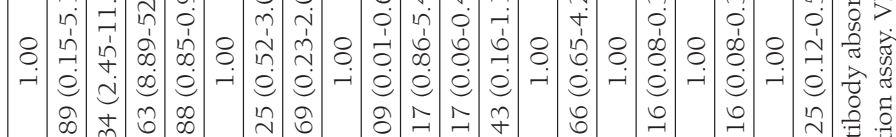

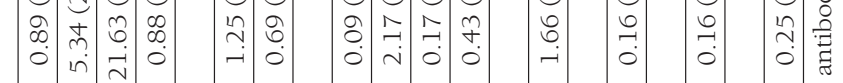

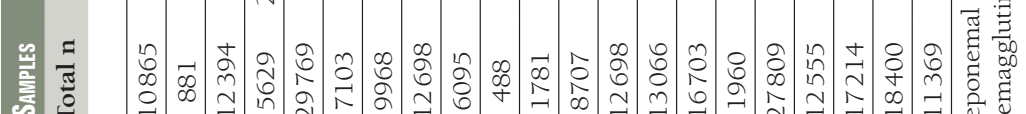

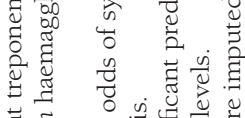

$\frac{z}{\frac{1}{2}}$

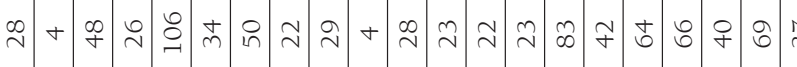

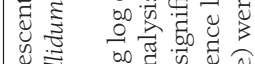
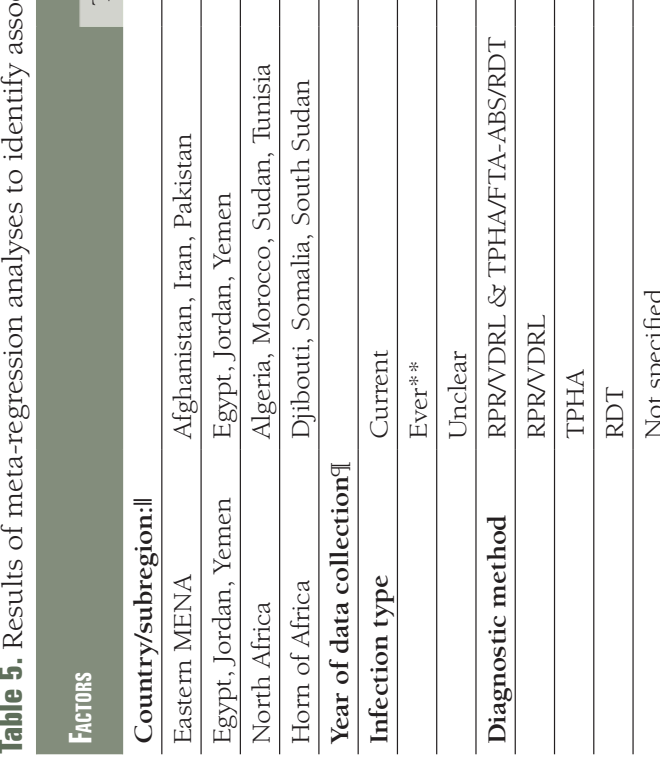

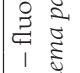

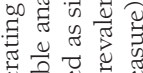

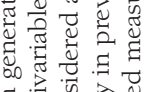

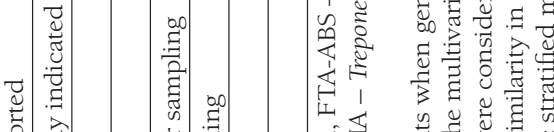

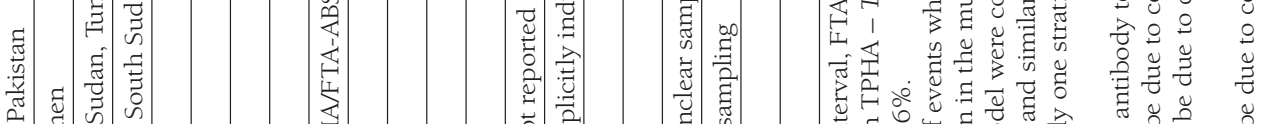

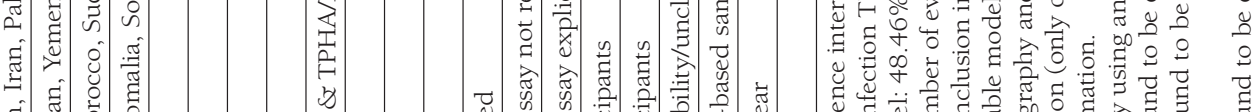

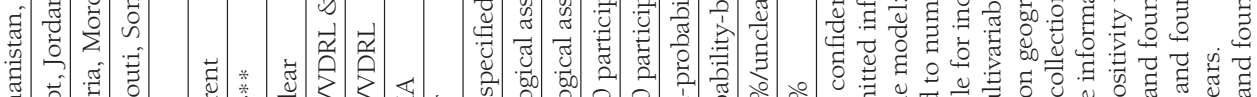

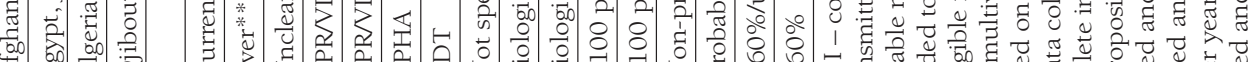

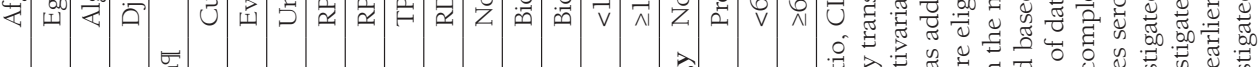

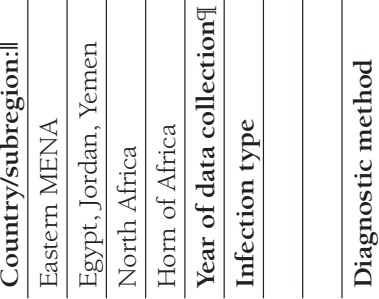

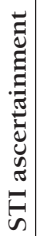

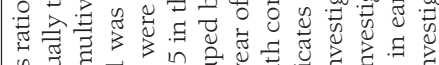

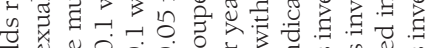

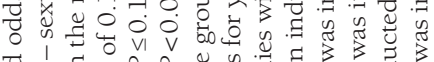

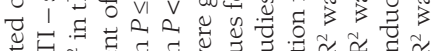

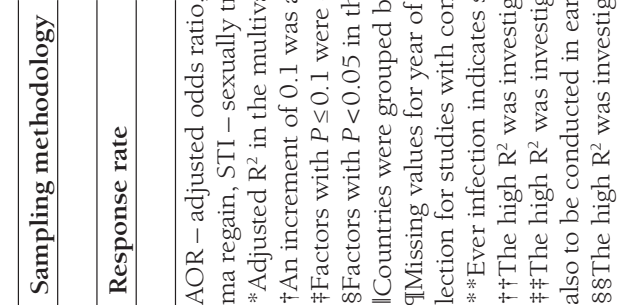


duration of active syphilis infection in FSWs or their sex partners [96,97], possibly because of improvements in syphilis diagnostics and treatment, or because of widespread use of antibiotics (including for non-STI infections, which sometimes may cure concurrent syphilis) [86].

This being said, recent surveillance data seems also to suggest an increase in syphilis incidence and/or prevalence in other sexual networks or in specific settings, such as among MSM [98-100], and even among reproductive-age women in few countries where congenital syphilis appears to be rising [101,102]. Contributors to these trends may include behavioral factors, such as more sexual partners and unprotected sex among MSM, as well as contextual factors, and possibly even biological factors [99,100,102-104].

Prevalence measures for syphilis and for C. trachomatis in FSWs in MENA were comparable to global levels $[22,23]$, but prevalence measures for $N$. gonorrhoeae and T. vaginalis leaned towards the lower end of the global range $[22,23]$. Even though the risk environment among FSWs in MENA seems less conducive to STI transmission, as compared to other regions [18], STI prevalence levels are substantial, perhaps affected by poor access to health care and prevention interventions [21,24,105], as well as absence of enabling environments for this vulnerable population, in a context of criminality [106,107] and stigma [108-110].

While interventions aiming at promoting safer sex, such as condom use, and STI etiological diagnosis and treatment, in high risk populations are widely accepted and advocated for [6,111-114], STI syndromic case management and presumptive treatment have been increasingly subject to criticism amid growing concerns about their role in promoting pathogens' antimicrobial resistance (AMR) [111,115-119]. Indeed, substantial AMR prevalence and multiple drug resistant strains have been found in gonococcal isolates from FSWs in sub-Saharan Africa [120,121] and elsewhere [122]. This suggests that despite the effectiveness of targeted STI treatment services in reducing STI incidence and prevalence, their appropriateness and sustainable implementation will need to be informed by surveillance and monitoring, notably for AMR, and thus may vary across settings [111,122]. This further supports WHO efforts towards building a global business case for accelerating development of STI vaccines as a fundamental solution to STI drug resistance [123-125].

This study is limited by the quantity and quality of available data. STI prevalence among FSWs remains unknown in over half of countries. While there was considerable evidence for syphilis, less evidence was found for C. trachomatis, N. gonorrhoeae, T. vaginalis, and HSV-2, limiting our ability to conduct advanced meta-analytics - meta-regressions were carried out only for syphilis. Though, for syphilis prevalence, the differences between current vs ever (seropositivity using antibody testing) infection, as well as the differences between diagnostics, were consistent with the findings of a large global analysis for the general population [86], the confidence intervals were wide owing to the smaller number of studies (Table 5). Several measures were based on routine data reporting, and did not include sufficient documentation of study methodology. There was also a wide array of diagnostics used for STI ascertainment, which may have affected observed prevalence.

Available studies may not be representative of the wider population of FSWs, or could be subject to biases, such as selection bias or detection bias. Of note, however, that there was no evidence that any of the assessed study-specific quality domains (Tables S5-S6 in Online Supplementary Document), including sampling methodology, response rate, and explicit indication of the assay used for infection ascertainment, had an effect on prevalence in the multivariable meta-regression (Table 5). Despite limitations, our study provided a detailed synthesis of STI epidemiology in FSWs in MENA, in a background of lack of evidence for this region $[22,23]$. A significant volume of published and unpublished data was identified and analyzed, and for the first time.

In conclusion, STI levels among FSWs are considerable, supporting a key role for CHSNs in STI transmission dynamics in MENA, and highlighting the public health needs of this neglected and vulnerable population. Despite the progress in our epidemiological understanding, major gaps persist, with no evidence being available for over half of MENA countries. With the limited STI surveillance $[24,126]$, and the focus of programmatic response on case management and syndromic approach, rather than being evidence-informed and grounded on etiological studies [24,126], there is a critical need to expand STI surveillance and the broader STI research agenda. STI testing should be part of IBBSS studies, as well as part of voluntary counseling and testing services for HIV [91,93]. Interventions should factor research findings to ensure adequate and efficient resource allocation. Without such expansion of STI efforts, it will not be possible to monitor infection trends, or to inform a public health response that attends to the WHO Global Health Sector Strategy on STIs [6]. 


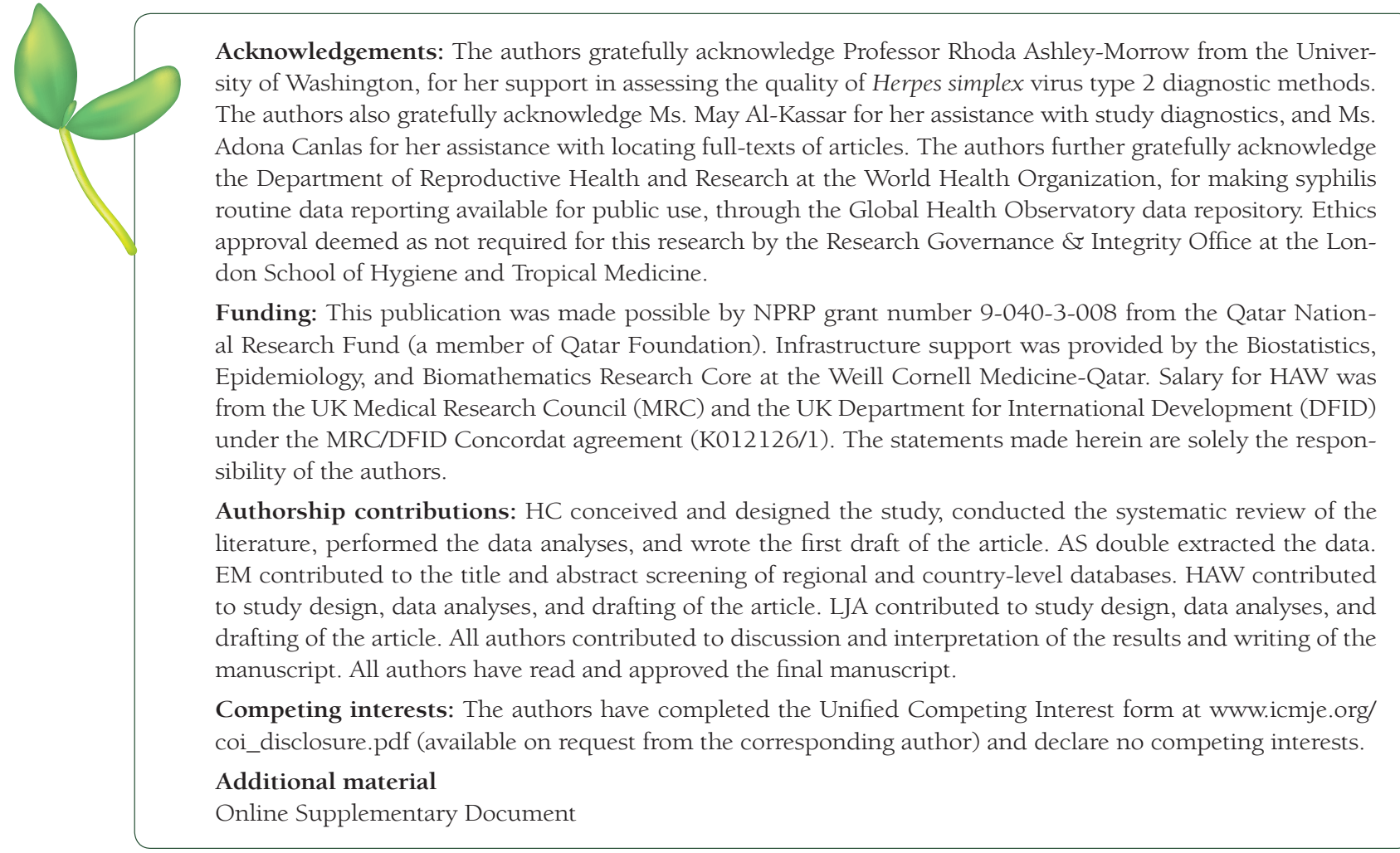

1 World Health Organization. Report on globally sexually transmitted infection surveillance 2015. Geneva, Switzerland: World Health Organization, 2016.

2 Newman L, Rowley J, Vander Hoorn S, Wijesooriya NS, Unemo M, Low N, et al. Global estimates of the prevalence and incidence of four curable sexually transmitted infections in 2012 based on systematic review and global reporting. PLoS One. 2015;10:e0143304. Medline:26646541 doi:10.1371/journal.pone.0143304

3 Looker KJ, Magaret AS, Turner KM, Vickerman P, Gottlieb SL, Newman LM. Global estimates of prevalent and incident herpes simplex virus type 2 infections in 2012. PLoS One. 2015;10:e114989. Medline:25608026 doi:10.1371/ journal.pone.0114989

4 Johnson LF, Lewis DA. The effect of genital tract infections on HIV-1 shedding in the genital tract: A systematic review and meta-analysis. Sex Transm Dis. 2008;35:946-59. Medline:18685546 doi:10.1097/OLQ.0b013e3181812d15

5 Cohen MS. Sexually transmitted diseases enhance HIV transmission: No longer a hypothesis. Lancet. 1998;351 Suppl 3:5-7. Medline:9652712 doi:10.1016/S0140-6736(98)90002-2

6 World Health Organization. Global health sector strategy on sexually transmitted infections, 2016-2021. Geneva, Switzerland: World Health Organization, 2016 Contract No.: WHO/RHR/16.09.

7 World Bank, Centers for Disease Prevention and Control. Sexually transmitted infections in developing countries. 2009. Accessed.

8 Thomas JC, Tucker MJ. The development and use of the concept of a sexually transmitted disease core. J Infect Dis. 1996;174 Suppl 2:S134-43. Medline:8843243 doi:10.1093/infdis/174.Supplement_2.S134

9 Kilmarx PH. Global epidemiology of HIV. Curr Opin HIV AIDS. 2009;4:240-6. Medline:19532059 doi:10.1097/COH. Ob013e32832c06db

10 Brunham RC, Plummer FA. A general model of sexually transmitted disease epidemiology and its implications for control. Med Clin North Am. 1990;74:1339-52. Medline:2246943 doi:10.1016/S0025-7125(16)30484-9

11 Omori R, Abu-Raddad LJ. Sexual network drivers of HIV and herpes simplex virus type 2 transmission. AIDS. 2017;31:1721-32. Medline:28514276 doi:10.1097/QAD.0000000000001542

12 Kouyoumjian SP, Heijnen M, Chaabna K, Mumtaz GR, Omori R, Vickerman P, et al. Global population-level association between herpes simplex virus 2 prevalence and HIV prevalence. AIDS. 2018;32:1343-52. Medline:29794495 doi:10.1097/QAD.0000000000001828

13 Abu-Raddad LJ, Schiffer JT, Ashley R, Mumtaz G, Alsallaq RA, Akala FA, et al. HSV-2 serology can be predictive of HIV epidemic potential and hidden sexual risk behavior in the Middle East and North Africa. Epidemics. 2010;2:173-82. Medline:21352788 doi:10.1016/j.epidem.2010.08.003

14 Omori R, Abu-Raddad LJ. Population sexual behavior and HIV prevalence in sub-Saharan Africa: Missing links? IJID. 2016;44:1-3. Medline:26780269 doi:10.1016/j.ijid.2016.01.005

15 Lee RM, Renzetti CM. The problems of researching sensitive topics. Am Behav Sci. 1990;33:510-28. doi:10.1177/0002764290033005002 
16 United Nations. Transforming our world: The 2030 agenda for sustainable development. 2015 A/RES/70/1.

17 Saba HF, Kouyoumjian SP, Mumtaz GR, Abu-Raddad LJ. Characterising the progress in HIV/AIDS research in the Middle East and North Africa. Sex Transm Infect. 2013;89 Suppl 3:iii5-9. Medline:23596206 doi:10.1136/sextrans-2012-050888

18 Chemaitelly H, Weiss HA, Thomas SL, Calvert C, Harfouche M, Abu-Raddad LJ. HIV epidemiology among female sex workers and their clients in the Middle East and North Africa: Systematic review, meta-analyses, and meta-regressions. BMC Med. 2019;17:119. Medline:31230594 doi:10.1186/s12916-019-1349-y

19 Mumtaz GR, Weiss HA, Thomas SL, Riome S, Setayesh H, Riedner G, et al. HIV among people who inject drugs in the Middle East and North Africa: Systematic review and data synthesis. PLoS Med. 2014;11:e1001663. Medline:24937136 doi:10.1371/journal.pmed.1001663

20 Mumtaz G, Hilmi N, McFarland W, Kaplan RL, Akala FA, Semini I, et al. Are HIV epidemics among men who have sex with men emerging in the Middle East and North Africa?: A systematic review and data synthesis. PLoS Med. 2010;8: e1000444. Medline:21829329 doi:10.1371/journal.pmed.1000444

21 Abu-Raddad LJ, Ghanem KG, Feizzadeh A, Setayesh H, Calleja JM, Riedner G. HIV and other sexually transmitted infection research in the Middle East and North Africa: Promising progress? Sex Transm Infect. 2013;89 Suppl 3:iiil-4. Medline:24191291 doi:10.1136/sextrans-2013-051373

22 Cwikel JG, Lazer T, Press F, Lazer S. Sexually transmissible infections among female sex workers: An international review with an emphasis on hard-to-access populations. Sex Health. 2008;5:9-16. Medline:18361849 doi:10.1071/SH07024

23 Platt L, Grenfell P, Fletcher A, Sorhaindo A, Jolley E, Rhodes T, et al. Systematic review examining differences in HIV, sexually transmitted infections and health-related harms between migrant and non-migrant female sex workers. Sex Transm Infect. 2013;89:311-9. Medline:23112339 doi:10.1136/sextrans-2012-050491

24 Abu-Raddad L, Akala FA, Semini I, Riedner G, Wilson D, Tawil O. Characterizing the HIV/AIDS epidemic in the Middle East and North Africa: Time for strategic action. World Bank/UNAIDS/WHO Publication, editor. Washington DC: The World Bank Press; 2010.

25 Abu-Raddad LJ, Hilmi N, Mumtaz G, Benkirane M, Akala FA, Riedner G, et al. Epidemiology of HIV infection in the Middle East and North Africa. AIDS. 2010;24:S5-23. Medline:20610949 doi:10.1097/01.aids.0000386729.56683.33

26 Higgins JPT, Green S. Cochrane Collaboration. Cochrane handbook for systematic reviews of interventions. Chichester, England; Hoboken, NJ: Wiley-Blackwell; 2015.

27 Moher D, Liberati A, Tetzlaff J, Altman DG, Group P. Preferred reporting items for systematic reviews and meta-analyses: The PRISMA statement. PLoS Med. 2009;6:e1000097. Medline:19621072 doi:10.1371/journal.pmed.1000097

28 World Health Organization. Global health observatory data repository. 2018. Available: http://apps.who.int/gho/data/ node.main.A1360STI?lang=en. Accessed.

29 International AIDS Society. Abstract archives of International AIDS Society conferences. Found at: http://wwwabstract-archiveorg/. Last accessed on 28th of July 2018.

30 Higgins JPT, Green S. Cochrane Collaboration. Cochrane handbook for systematic reviews of interventions. Chichester, England; Hoboken, NJ: Wiley-Blackwell; 2008.

31 Ashley RL, Militoni J, Lee F, Nahmias A, Corey L. Comparison of western blot (immunoblot) and glycoprotein G-specific immunodot enzyme assay for detecting antibodies to herpes simplex virus types 1 and 2 in human sera. J Clin Microbiol. 1988;26:662-7. Medline:2835389

32 Ashley RL. Performance and use of HSV type-specific serology test kits. Herpes. 2002;9:38-45. Medline:12106510

33 Freeman MF, Tukey JW. Transformations related to the angular and the square root. Ann Math Stat. 1950;21:607-11. doi:10.1214/aoms/1177729756

34 Miller JJ. The inverse of the Freeman - Tukey double arcsine transformation. Am Stat. 1978;32:138.

35 Barendregt JJ, Doi SA, Lee YY, Norman RE, Vos T. Meta-analysis of prevalence. J Epidemiol Community Health. 2013;67:974-8. Medline:23963506 doi:10.1136/jech-2013-203104

36 DerSimonian R, Laird N. Meta-analysis in clinical trials. Control Clin Trials. 1986;7:177-88. Medline:3802833 doi:10.1016/0197-2456(86)90046-2

37 Borenstein M. Introduction to meta-analysis. Chichester, U.K.: John Wiley \& Sons; 2009.

38 Higgins JP, Thompson SG. Quantifying heterogeneity in a meta-analysis. Stat Med. 2002;21:1539-58. Medline:12111919 doi:10.1002/sim.1186

39 R core team. R: A language and environment for statistical computing. Vienna, Austria: R Foundation for Statistical Computing; 2017.

40 StataCorp. Stata statistical software: Release 15.1. College Station, TX: StataCorp LP; 2017.

41 Kazerooni PA, Motazedian N, Motamedifar M, Sayadi M, Sabet M, Lari MA, et al. The prevalence of human immunodeficiency virus and sexually transmitted infections among female sex workers in Shiraz, south of Iran: By respondent-driven sampling. Int J STD AIDS. 2014;25:155-61. Medline:23970644 doi:10.1177/0956462413496227

42 Navadeh S, Mirzazadeh A, Mousavi L, Haghdoost A, Fahimfar N, Sedaghat A. HIV, HSV2 and syphilis prevalence in female sex workers in Kerman, South-East Iran; using respondent-driven sampling. Iran J Public Health. 2012;41:605. Medline:23641392

43 Ahmed HJ, Omar K, Adan SY, Guled AM, Grillner L, Bygdeman S. Syphilis and human immunodeficiency virus seroconversion during a 6-month follow-up of female prostitutes in Mogadishu, Somalia. Int J STD AIDS. 1991;2:119-23. Medline:2043703 doi:10.1177/095646249100200209 
44 Todd CS, Nasir A, Stanekzai MR, Bautista CT, Botros BA, Scott PT, et al. HIV, hepatitis B, and hepatitis C prevalence and associated risk behaviors among female sex workers in three Afghan cities. AIDS. 2010;24 Suppl 2:S69-75. Medline:20610952 doi:10.1097/01.aids.0000386736.25296.8d

45 Ministry of Health and Population, National AIDS Program. Evaluation of selected reproductive health infections in various Egyptian population groups in Greater Cairo. Cairo, Egypt: 2000.

46 Kassaian N, Ataei B, Yaran M, Babak A, Shoaei P, Ataie M. HIV and other sexually transmitted infections in women with illegal social behavior in Isfahan, Iran. Adv Biomed Res. 2012;1:5. Medline:23210064 doi:10.4103/2277-9175.94427

47 Jahanbakhsh F, Bagheri Amiri F, Sedaghat A, Fahimfar N, Mostafavi E. Prevalence of HAV Ab, HEV (IgG), HSV2 IgG, and syphilis among sheltered homeless adults in Tehran, 2012. Int J Health Policy Manag. 2017;7:225-30. Medline:29524951 doi:10.15171/ijhpm.2017.74

48 Royaume du Maroc-Ministere de la Sante. Etude de prevalence des IST chez les femmes qui consultent pour pertes vaginales et/ou douleurs du bas ventre. Rabat, Maroc: Programme National de lutte contre les IST/SIDA, 2008.

49 Ministry of Health-Morocco, The Joint United Nations Programme on HIV/AIDS (UNAIDS), The Global Fund. HIV integrated behavioral and biological surveillance surveys-Morocco 2011: Female sex workers in Agadir, Fes, Rabat and Tanger. Morocco: 2012.

50 Baqi S, Nabi N, Hasan SN, Khan AJ, Pasha O, Kayani N, et al. HIV antibody seroprevalence and associated risk factors in sex workers, drug users, and prisoners in Sindh, Pakistan. J Acquir Immune Defic Syndr Hum Retroviro. 1998;18:739. Medline:9593461 doi:10.1097/00042560-199805010-00011

51 Rehan N, Bokhari A, Nizamani NM, Jackson D, Naqvi HR, Qayyum K, et al. National study of reproductive tract infections among high risk groups of Lahore and Karachi. J Coll Physicians Surg Pak. 2009;19:228-31. Medline:19356337

52 Ministry of Health-Pakistan National AIDS Control Program. National study of reproductive tract and sexually transmitted infections: A survey of high risk groups in Lahore and Karachi, Pakistan. 2005.

53 Shah AS, Memon MA, Soomro S, Kazi N, Kristensen S, editors. Seroprevelance of HIV, syphilis, hepatitis B and hepatitis C among female commercial sex workers in Hyderabad, Pakistan. International AIDS Conference, C12368; 2004.

54 Hawkes S, Collumbien M, Platt L, Lalji N, Rizvi N, Andreasen A, et al. HIV and other sexually transmitted infections among men, transgenders and women selling sex in two cities in Pakistan: A cross-sectional prevalence survey. Sex Transm Infect. 2009;85:ii8-16. Medline:19307351 doi:10.1136/sti.2008.033910

55 Khan MS, Unemo M, Zaman S, Lundborg CS. HIV, STI prevalence and risk behaviours among women selling sex in Lahore, Pakistan. BMC Infect Dis. 2011;11:119. Medline:21569319 doi:10.1186/1471-2334-11-119

56 Jama H, Hederstedt B, Osman S, Omar K, Isse A, Bygdeman S. Syphilis in women of reproductive age in Mogadishu, Somalia: Serological survey. Genitourin Med. 1987;63:326-8. Medline:3500110 doi:10.1136/sti.63.5.326

57 Scott DA, Corwin AL, Constantine NT, Omar MA, Guled A, Yusef M, et al. Low prevalence of human immunodeficiency virus-1 (HIV-1), HIV-2, and human T cell lymphotropic virus-1 infection in Somalia. Am J Trop Med Hyg. 1991;45:6539. Medline:1763791 doi:10.4269/ajtmh.1991.45.653

58 Corwin AL, Olson JG, Omar MA, Razaki A, Watts DM. HIV-1 in Somalia: Prevalence and knowledge among prostitutes. AIDS. 1991;5:902-4. Medline:1892603 doi:10.1097/00002030-199107000-00023

59 Watts DM, Corwin AL, Omar MA, Hyams KC. Low risk of sexual transmission of hepatitis C virus in Somalia. Trans R Soc Trop Med Hyg. 1994;88:55-6. Medline:8154002 doi:10.1016/0035-9203(94)90495-2

60 International Organization for Migration (IOM). Integrated biological and behavioural surveillance survey among vulnerable women in Hargeisa, Somaliland. Geneva, Switzerland: 2017.

61 Government of the Republic of South Sudan-Ministry of Health. A bio-behavioral HIV survey of female sex workers in South Sudan. South Sudan: 2016

62 Bchir A, Jemni L, Saadi M, Milovanovic A, Brahim H, Catalan F. Markers of sexually transmitted diseases in prostitutes in central Tunisia. Genitourin Med. 1988;64:396-7. Medline:3224977 doi:10.1136/sti.64.6.396-a

63 Ayachi F, Kechrid A, Lagha N, Ben Hamida A, Amamou H, Ben Mahmoud R. Seroprevalence rate of syphilis in 3 groups of sexually active tunisian women. [French]. Med Mal Infect. 1997;27:913-4. doi:10.1016/S0399-077X(97)80249-1

64 Stulhofer A, Bozicevic I. HIV bio-behavioural survey among female sex workers in Aden, Yemen. 2008.

65 National AIDS Control Program, Johns Hopkins University Bloomberg School of Public Health HIV Surveillance Project. Integrated behavioral \& biological surveillance (IBBS) in Afghanistan: Year 1 report. Kabul, Afghanistan: 2010.

66 National AIDS Control Program, Johns Hopkins University Bloomberg School of Public Health HIV Surveillance Project. Integrated biological \& behavioral surveillance (IBBS) in selected cities of Afghanistan: Findings of 2012 IBBS survey and comparison to 2009 IBBS survey. Kabul, Afghanistan: National AIDS Control Program; 2012

67 Ministere de la Sante et de la Population et de la Reforme Hospitaliere. Direction de la Prevention Comite National de Lutte contre les IST/VIH/SIDA. Plan national strategique de lutte contre les IST/VIH/Sida 2008-2012. Geneva, Switzerland: Ministere de la Sante et de la Population et de la Reforme Hospitaliere; 2009.

68 Mirzazadeh A, Shokoohi M, Khajehkazemi R, et al, editors. HIV and sexually transmitted infections among female sex workers in Iran: Findings from the 2010 and 2015 national surveillance surveys. 21st International AIDS Conference, Durban, South Africa, 7/18-22, ePoster, Abstract TUPEC175; 2016.

69 Bibi I, Devrajani BR, Shah SZA, Soomro MH, Jatoi MA. Frequency of syphilis in female sex workers at red light area of Hyderabad, Pakistan. J Pak Med Assoc. 2010;60:353-6. Medline:20527605

70 Raza M, Ikram N, Saeed N, Waheed U, Kamran M, Iqbal R, et al. HIV/AIDS and syphilis screening among high risk groups. J Rawal Med Coll. 2015;19:11-4. 
71 Burans JP, Fox E, Omar MA, Farah AH, Abbass S, Yusef S, et al. HIV infection surveillance in Mogadishu, Somalia. East Afr Med J. 1990;67:466-72. Medline:2226225

72 Sudan National AIDS Control Program. Integrated bio-behavioral HIV surveillance (IBBS) among female sex workers and men who have sex with men in 15 states of Sudan, 2011-2012. 2012.

73 Znazen A, Frikha-Gargouri O, Berrajah L, Bellalouna S, Hakim H, Gueddana N, et al. Sexually transmitted infections among female sex workers in Tunisia: High prevalence of Chlamydia trachomatis. Sex Transm Infect. 2010;86:500-5. Medline:20656718 doi:10.1136/sti.2010.042770

74 Additional country-level data provided through the MENA HIV/AIDS Epidemiology Synthesis Project database by the World Health Organization Regional Office for the Eastern Mediterranean. 2013.

75 Moayedi-Nia S, Bayat Jozani Z, Esmaeeli Djavid G, Entekhabi F, Bayanolhagh S, Saatian M, et al. HIV, HCV, HBV, HSV, and syphilis prevalence among female sex workers in Tehran, Iran, by using respondent-driven sampling. AIDS Care. 2016;28:487-90. Medline:26565671 doi:10.1080/09540121.2015.1109582

76 Khattabi H, Alami K. Surveillance sentinelle du VIH: Resultats 2004 et tendances de la seroprevalence du VIH. Morocco: 2005.

77 Bennani A., Alami K. Surveillance sentinelle du VIH: Resultats 2005 et tendances de la seroprevalence du VIH. 2006.

78 Kadi Z, Bouguermouh A, Ait-Mokhtar N, Allouache A, Ziat A, Orfilla J. Genital chlamydia infections. A seroepidemiologic study in Algiers. [French]. Arch Inst Pasteur Alger. 1989;57:73-82. Medline:2489406

79 Darougar S, Aramesh B, Gibson JA, Treharne JD, Jones BR. Chlamydial genital infection in prostitutes in Iran. Br J Vener Dis. 1983;59:53-5. Medline:6824908 doi:10.1136/sti.59.1.53

80 World Health Organization. HIV surveillance systems: Regional update 2011. Geneva: WHO; 2011.

81 Nasirian M, Kianersi S, Hoseini SG, Kassaian N, Yaran M, Shoaei P, et al. Prevalence of sexually transmitted infections and their risk factors among female sex workers in Isfahan, Iran: A cross-sectional study. J Int Assoc Provid AIDS Care. 2017;16:608-14. Medline:29017374 doi:10.1177/2325957417732836

82 Taghizadeh H, Taghizadeh F, Fathi M, Reihani P, Shirdel N, Rezaee SM. Drug use and high-risk sexual behaviors of women at a drop-in center in mazandaran province, Iran, 2014. IJPBS. 2015;9:e1047-55. Medline:26288640 doi:10.17795/ ijpbs 1047

83 Programme de Lutte contre les IST/SIDA. Analyse de la situation et de la reponse au VIH/SIDA en Tunisie. Tunisia: 2005.

84 Vafaei H, Asadi N, Foroughinia L, Salehi A, Kuhnavard S, Akbarzadeh M, et al. Comparison of abnormal cervical cytology from HIV positive women, female sex workers, and general population. IJCBNM. 2015;3:76-83. Medline:26005687

85 Ibrahim AI, Kouwatli KM, Obeid MT. Frequency of herpes simplex virus in Syria based on type-specific serological assay. Saudi Med J. 2000;21:355-60. Medline:11533818

86 Smolak A, Rowley J, Nagelkerke N, Kassebaum NJ, Chico RM, Korenromp EL, et al. Trends and predictors of syphilis prevalence in the general population: Global pooled analyses of 1103 prevalence measures including 136 million syphilis tests. Clin Infect Dis. 2018;66:1184-91. Medline:29136161 doi:10.1093/cid/cix975

87 Bozicevic I, Riedner G, Calleja JM. HIV surveillance in MENA: Recent developments and results. Sex Transm Infect. 2013;89 Suppl 3:iiil1-6. Medline:23434789 doi:10.1136/sextrans-2012-050849

88 Vandepitte J, Lyerla R, Dallabetta G, Crabbe F, Alary M, Buve A. Estimates of the number of female sex workers in different regions of the world. Sex Transm Infect. 2006;82 Suppl 3:iiil8-25. Medline:16735288 doi:10.1136/sti.2006.020081

89 Kouyoumjian SP, El Rhilani H, Latifi A, El Kettani A, Chemaitelly H, Alami K, et al. Mapping of new HIV infections in Morocco and impact of select interventions. IJID. 2018;68:4-12. Medline:29253710 doi:10.1016/j.ijid.2017.12.013

90 Mumtaz GR, Riedner G, Abu-Raddad LJ. The emerging face of the HIV epidemic in the Middle East and North Africa. Curr Opin HIV AIDS. 2014;9:183-91. Medline:24445372 doi:10.1097/COH.0000000000000038

91 World Health Organization. Strategies and laboratory methods for strengthening surveillance of sexually transmitted infections 2012. Geneva, Switzerland: World Health Organization, 2012.

92 Munro M, Holte-McKenzie M, Ahmed S, Archibald CP, Blanchard JF, Thompson LH. Second generation HIV surveillance in Pakistan: Policy challenges and opportunities. Sex Transm Infect. 2013;89:ii48-52. Medline:23220785 doi:10.1136/ sextrans-2012-050773

93 Reintjes R, Wiessing L. 2nd-generation HIV surveillance and injecting drug use: Uncovering the epidemiological iceberg. Int J Public Health. 2007;52:166-72. Medline:17958283 doi:10.1007/s00038-007-5123-0

94 Awad SF, Abu-Raddad LJ. Could there have been substantial declines in sexual risk behavior across sub-Saharan Africa in the mid-1990s? Epidemics. 2014;8:9-17. Medline:25240899 doi:10.1016/j.epidem.2014.06.001

95 Kenyon CR, Osbak K, Buyze J, Chico RM. The changing relationship between bacterial STIs and HIV prevalence in South Africa - an ecological study. Int J STD AIDS. 2015;26:556-64. Medline:25122576 doi:10.1177/0956462414546392

96 Osbak KK, Rowley JT, Kassebaum NJ, Kenyon CR. The prevalence of syphilis from the early HIV period is correlated With peak HIV prevalence at a country level. Sex Transm Dis. 2016;43:255-7. Medline:26967303 doi:10.1097/ OLQ.0000000000000422

97 Kenyon CR, Osbak K, Tsoumanis A. The global epidemiology of syphilis in the past century - a systematic review based on antenatal syphilis prevalence. PLoS Negl Trop Dis. 2016;10:e0004711. Medline:27167068 doi:10.1371/journal. pntd.0004711

98 Tucker JD, Cohen MS. China's syphilis epidemic: epidemiology, proximate determinants of spread, and control responses. Curr Opin Infect Dis. 2011;24:50-5. Medline:21150594 doi:10.1097/QCO.0b013e32834204bf

99 Stamm LV. Global challenge of antibiotic-resistant Treponema pallidum. Antimicrob Agents Chemother. 2010;54:5839. Medline:19805553 doi:10.1128/AAC.01095-09 
100 Mohammed H, Mitchell H, Sile B, Duffell S, Nardone A, Hughes G. Increase in sexually transmitted infections among men who have sex with men, England, 2014. Emerg Infect Dis. 2016;22:88-91. Medline:26689861 doi:10.3201/ eid2201.151331

101 Centers for Disease Control and Prevention. Increase in incidence of congenital syphilis — United States, $2012-2014$. Atlanta, USA: 2015

102 Chen ZQ, Zhang GC, Gong XD, Lin C, Gao X, Liang GJ, et al. Syphilis in China: Results of a national surveillance programme. Lancet. 2007;369:132-8. Medline:17223476 doi:10.1016/S0140-6736(07)60074-9

103 Tucker JD, Cohen MS. China's syphilis epidemic: Epidemiology, proximate determinants of spread, and control responses. Curr Opin Infect Dis. 2011;24:50-5. Medline:21150594 doi:10.1097/QCO.0b013e32834204bf

104 Stoltey JE, Cohen SE. Syphilis transmission: a review of the current evidence. Sex Health. 2015;12:103-9. Medline:25702043 doi:10.1071/SH14174

105 Al-Thani A, Abdul-Rahim H, Alabsi E, Bsaisu HN, Haddad P, Mumtaz GR, et al. Prevalence of Chlamydia trachomatis infection in the general population of women in Qatar. Sex Transm Infect. 2013;89:iii57-60. Medline:23863874 doi:10.1136/sextrans-2013-051169

106 Abu-Raddad LJ, Akala FA, Semini I, Riedner G, Wislon D, Tawil O. Policy notes. Characterizing the HIV/AIDS epidemic in the Middle East and North Africa: time for strategic action. Middle East and North Africa HIV/AIDS Epidemiology Synthesis Project. World Bank/UNAIDS/WHO publication. Washington DC: The World Bank Press; 2010.

107 Jenkins C, Robalino DA. HIV/AIDS in the Middle East and North Africa: The costs of inaction. Washigton, D.C.: The World Bank; 2003

108 Mohebbi MR. Female sex workers and fear of stigmatisation [2]. Sex Transm Infect. 2005;81:180-1. Medline:15800100 doi:10.1136/sti.2004.010512

109 Dejong J, Mortagy I. The struggle for recognition by people living with HIV/AIDS in Sudan. Qual Health Res. 2013;23:782-94. Medline:23515299 doi:10.1177/1049732313482397

110 DeJong J, Mahfoud Z, Khoury D, Barbir F, Afifi RA. Ethical considerations in HIV/AIDS biobehavioral surveys that use respondent-driven sampling: Illustrations from Lebanon. Am J Public Health. 2009;99:1562-7. Medline:19608961 doi:10.2105/AJPH.2008.144832

111 Mayaud P, Mabey D. Approaches to the control of sexually transmitted infections in developing countries: old problems and modern challenges. Sex Transm Infect. 2004;80:174-82. Medline:15169997 doi:10.1136/sti.2002.004101

112 Grund JM, Bryant TS, Jackson I, Curran K, Bock N, Toledo C, et al. Association between male circumcision and women's biomedical health outcomes: A systematic review. Lancet Glob Health. 2017;5:e1113-22. Medline:29025633 doi:10.1016/S2214-109X(17)30369-8

113 Morris BJ, Hankins CA. Effect of male circumcision on risk of sexually transmitted infections and cervical cancer in women. Lancet Glob Health. 2017;5:e1054-5. Medline:29025620 doi:10.1016/S2214-109X(17)30386-8

114 World Health Organization. Implementing comprehensive HIV/STI programmes with sex workers. Geneva, Switzerland: WHO; 2013.

115 Wi T, Lahra MM, Ndowa F, Bala M, Dillon JR, Ramon-Pardo P, et al. Antimicrobial resistance in Neisseria gonorrhoeae: Global surveillance and a call for international collaborative action. PLoS Med. 2017;14:e1002344. Medline:28686231 doi:10.1371/journal.pmed.1002344

116 Lewis DA. Global resistance of Neisseria gonorrhoeae: When theory becomes reality. Curr Opin Infect Dis. 2014;27:627. Medline:24275696 doi:10.1097/QCO.0000000000000025

117 Bolan GA, Sparling PF, Wasserheit JN. The emerging threat of untreatable gonococcal infection. N Engl J Med. 2012;366:485-7. Medline:22316442 doi:10.1056/NEJMp1112456

118 Kirkcaldy RD, Harvey A, Papp JR, Del Rio C, Soge OO, Holmes KK, et al. Neisseria gonorrhoeae antimicrobial susceptibility surveillance - The Gonococcal Isolate Surveillance Project, 27 sites, United States, 2014. MMWR Surveill Summ. 2016;65:1-19. Medline:27414503 doi:10.15585/mmwr.ss6507al

119 Suay-Garcia B, Perez-Gracia MT. Future prospects for Neisseria gonorrhoeae treatment. Antibiotics (Basel). $2018 ; 7$ :E49. Medline:29914071 doi:10.3390/antibiotics7020049

120 Mason PR, Gwanzura L, Latif AS, Marowa E, Ray S, Katzenstein DA. Antimicrobial resistance in gonococci isolated from patients and from commercial sex workers in Harare, Zimbabwe. Int J Antimicrob Agents. 1997;9:175-9. Medline:9552714 doi:10.1016/S0924-8579(97)00052-6

121 Ssemwanga D, Ndembi N, Lyagoba F, Magambo B, Kapaata A, Bukenya J, et al. Transmitted antiretroviral drug resistance among drug-naive female sex workers with recent infection in Kampala, Uganda. Clin Infect Dis. 2012;54 Suppl 4:S339-42. Medline:22544200 doi:10.1093/cid/cir937

122 Abraha M, Egli-Gany D, Low N. Epidemiological, behavioural, and clinical factors associated with antimicrobial-resistant gonorrhoea: a review. F1000Res. 2018;7:400. Medline:29636908 doi:10.12688/f1000research.13600.1

123 Gottlieb SL, Low N, Newman LM, Bolan G, Kamb M, Broutet N. Toward global prevention of sexually transmitted infections (STIs): the need for STI vaccines. Vaccine. 2014;32:1527-35. Medline:24581979 doi:10.1016/j.vaccine.2013.07.087

124 Gottlieb SL, Deal CD, Giersing B, Rees H, Bolan G, Johnston C, et al. The global roadmap for advancing development of vaccines against sexually transmitted infections: Update and next steps. Vaccine. 2016;34:2939-47. Medline:27105564 doi:10.1016/j.vaccine.2016.03.111

125 Broutet N, Fruth U, Deal C, Gottlieb SL, Rees H. participants of the STIVTC. Vaccines against sexually transmitted infections: the way forward. Vaccine. 2014;32:1630-7. Medline:24480024 doi:10.1016/j.vaccine.2014.01.053

126 World Health Organization Office for the Eastern Mediterranean Region (WHO-EMRO). Technical paper on the regional strategy for STI prevention and control in the Eastern Mediterranean Region of WHO presented at the regional committee 55. Unpublished. 